\title{
Fe-S cluster assembly in the supergroup Excavata
}

\author{
Priscila Peña-Diaz ${ }^{1}$ Julius Lukeš ${ }^{1,2}$
}

Received: 15 February 2018 / Accepted: 29 March 2018 / Published online: 5 April 2018

(c) The Author(s) 2018, corrected publication May/2018

\begin{abstract}
The majority of established model organisms belong to the supergroup Opisthokonta, which includes yeasts and animals. While enlightening, this focus has neglected protists, organisms that represent the bulk of eukaryotic diversity and are often regarded as primitive eukaryotes. One of these is the "supergroup" Excavata, which comprises unicellular flagellates of diverse lifestyles and contains species of medical importance, such as Trichomonas, Giardia, Naegleria, Trypanosoma and Leishmania. Excavata exhibits a continuum in mitochondrial forms, ranging from classical aerobic, cristae-bearing mitochondria to mitochondria-related organelles, such as hydrogenosomes and mitosomes, to the extreme case of a complete absence of the organelle. All forms of mitochondria house a machinery for the assembly of Fe-S clusters, ancient cofactors required in various biochemical activities needed to sustain every extant cell. In this review, we survey what is known about the $\mathrm{Fe}-\mathrm{S}$ cluster assembly in the supergroup Excavata. We aim to bring attention to the diversity found in this group, reflected in gene losses and gains that have shaped the Fe-S cluster biogenesis pathways.
\end{abstract}

Keywords $\mathrm{Fe}-\mathrm{S}$ cluster $\cdot$ Mitochondria $\cdot$ Excavata $\cdot$ Evolution

\section{Introduction}

The intimate relationship between eukaryotic cells and mitochondria, as endosymbiont-derived organelles, has taken billion of years to establish $[1,2]$. It was initially accepted that the basis for the presence of mitochondria in virtually every eukaryotic cell had been the provision of energy from their oxidative phosphorylation machinery, yet several lines of evidence have proven otherwise [3]. The description of various types of mitochondria and mitochondria-related organelles (or MRO), many of which are found in a spectrum of unrelated protist clades, has brought into the spotlight an enormous organellar diversity, or what is rather a continuum, ranging from a minimalistic MRO of Giardia to the highly complex mitochondria of trypanosomes [4]. MROs have been found in eukaryotic supergroups Excavata, SAR

The original version of this article was revised due to a retrospective Open Access order.

Priscila Peña-Diaz

pena@paru.cas.cz

1 Institute of Parasitology, Biology Centre, Czech Academy of Sciences, České Budějovice (Budweis), Czech Republic

2 Faculty of Sciences, University of South Bohemia, České Budějovice (Budweis), Czech Republic
(stramenopiles/alveolates/Rhizaria), photosynthetic algae, and Opisthokonta [1, 5]. Organelles of mitochondrial origin, of which MROs form a part, have been classified into five types [5]: (1) "classical mitochondrion" with a complete electron transport chain, which is capable of using oxygen as an electron acceptor, and produces metabolic energy from such machinery; ( 2 and 3 ) organelles that bear a functional electron transport chain, yet use other electron acceptors such as fumarate, and are capable of performing both substrate-level phosphorylation and may or may not produce $\mathrm{H}_{2}$; (4) double membrane-bound MROs called hydrogenosomes that are capable of ATP production in anaerobic or microaerophilic environments and excrete $\mathrm{H}_{2}$ as one of the end products of substrate-level phosphorylation in an organelle lacking electron transport chain [6]; finally, (5) mitosomes represent a type of MRO incapable of energy production, as they lack the components of an active electron chain and mostly have lost their genome [1,5].

Remarkably, the $\mathrm{Fe}-\mathrm{S}$ cluster assembly pathway is the only known common denominator of this conglomerate of organelles. Moreover, in one of the best-studied eukaryotes, the yeast Saccharomyces cerevisiae, this pathway seems to be the only truly essential component of its mitochondria [3,7]. In this review, we revise what is known about the $\mathrm{Fe}-\mathrm{S}$ cluster assembly pathways of the unicellular 
supergroup Excavata and attempt to compare its inventory with those described in other eukaryotes, but mostly in the Opisthokonta, the by far most studied supergroup that includes, not surprisingly, humans [8].

$\mathrm{Fe}-\mathrm{S}$ clusters are ancient cofactors found in the whole spectrum of life. In Archaea, Bacteria and Eukaryota, cells have evolved different machineries for their $\mathrm{Fe}-\mathrm{S}$ clusters assembly, namely the methanoarchaeal sulfur mobilization (SUF) machinery [9], the nitrogen fixation (NIF) pathway [10], the cysteine sulfinate desulfinate (CSD) system [11], the iron-sulfur cluster assembly (ISC) pathway $[12,13]$ and cytosolic iron-sulfur protein assembly (CIA) pathway [14-16]. The first one is present throughout bacteria and in the chloroplasts of photosynthesizing organisms [17], while the NIF system was initially discovered in the maturation of nitrogenase in $\mathrm{N}_{2}$-fixing bacteria [18]. The CSD system has been described in Escherichia coli as a partial functional homolog of the SUF system [19]. The ISC pathway is associated with eubacteria and in eukaryotes located within the mitochondria [3]. Finally, the CIA machinery is found in the cytosol of eukaryotes, where it assembles, with the assistance of mitochondrial ISC, Fe-S clusters eventually incorporated into proteins located in this cellular compartment $[14,20]$. It is now widely accepted that the latter pathway was bequeathed from an endosymbiont to an ancestral eukaryote, while the plastid-bearing eukaryotes inherited their SUF machinery from an early cyanobacterium [17, 21, 22]. On the other hand, a lateral gene transfer has been proposed to be behind the emergence of the SUF pathway in some unicellular eukaryotes that either retain highly diverged MROs, such as Blastocystis, Stygiella incarcerata and Pygsuia biforma, or lost the entire organelle, along with the ISC pathway, like in the case of Monocercomonoides [23]. In any case, the $\mathrm{Fe}-\mathrm{S}$ cluster assembly represents a hallmark that is always taken into account when analyzing the evolution of divergent mitochondria-derived organelles $[12,24-28]$.

\section{Fe-S cluster machineries: a brief overview}

\section{Bacterial systems}

The Fe-S cluster assembly machineries in bacteria can be subdivided into four systems mentioned above, their distribution being species specific $[18,29,30]$. As an example, $E$. coli with the best-studied bacterial $\mathrm{Fe}-\mathrm{S}$ assemblies exhibits the ISC, the SUF and the CSD systems [18, 19]. These distinct systems share the main activities for the formation of a $[2 \mathrm{Fe}-2 \mathrm{~S}]$ cluster, which may be divided into three main stages: (1) Pyridoxal 5'-phosphate-dependent cysteine (Cys) desulfuration with concomitant production of L-alanine, carried out by a cysteine desulfurase (CD). The ISC, SUF, CSD and NIF systems each bear a functional homolog of this enzyme which, however, displays significant differences addressed below. (2) Assembly of an Fe-S cluster on a scaffold protein; a Cys in the scaffold protein binds sulfur liberated from the previous reaction, which physically interacts with the CD for the Fe-S assembly to occur. (3) Transfer of the $\mathrm{Fe}-\mathrm{S}$ cluster from the $\mathrm{CD}$-scaffold complex onto a delivery protein, which will subsequently interact with the recipient proteins and install the cluster.

\section{The ISC system}

The Fe-S cluster assembly by the ISC system involves the activity of at least five proteins. A cysteine desulfurase (IscS) provides the sulfur, while the formation of the cluster takes place on the scaffold protein named IscU. Ferredoxin (Fdx) likely acts as an electron donor in this reaction [31, 32]. Subsequently, IscU requires the assistance of the chaperones HscA (heat shock cognate $66 \mathrm{kDa}$ or Hsc66) and $\mathrm{HscB}$ (heat shock cognate $20 \mathrm{kDa}$ or $\mathrm{Hsc} 20$ ). HscA is a member of the Hsp70/DnaK chaperone family and exhibits an intrinsic ATPase activity, while HscB belongs to the Hsc20/DnaJ J-type co-chaperone family [33]. The binding of the chaperones, which is mediated by an LPPVK motif found in IscU, occurs in an orderly fashion to release the nascent $\mathrm{Fe}-\mathrm{S}$ cluster onto the delivery system in an ATPdependent manner [34-37]. In this scenario, HscA binds IscU, enhanced by the presence of $\mathrm{HscB}$, which increases the ATPase activity of the former chaperone by approximately 400 -fold [35, 38]. The binding model formulated based on the studies of the IscU mutants proposes that the chaperone complex stabilizes IscU for the release of the cluster to the receptor protein [39]. IscU has also been observed to interact with both [2Fe-2S] and [4Fe-4S] clusters [40]. This was further analyzed upon the binding of the scaffold protein to Fdx, which has been proposed to mediate, at least partially and in vitro, the reductive coupling of $[2 \mathrm{Fe}-2 \mathrm{~S}]$ clusters into [4Fe-4S] clusters [41]. Once the $\mathrm{Fe}-\mathrm{S}$ cluster has been assembled, it is transferred to the delivery system for further insertion into apoproteins, a role carried out by the dedicated protein IscA. The bacterial frataxin, named CyaY, plays an inhibitory role in the biogenesis of the Fe-S cluster assembly by binding to IscS in an iron-sensing regulatory role [42].

\section{The SUF system}

The SUF system for the Fe-S cluster assembly is induced by iron-depleted and oxidative stress conditions and mainly involves the activity of two sub-complexes [9]. Proteins SufE and SufS form the heterodimer SufSE, while a second sub-complex termed SufBCD is composed of SufB, SufC and SufD $[43,44]$. SufS, which represents the CD and therefore is an ortholog of IscS, collaborates with SufE, which 
increases the desulfurase activity of the CD [43, 45, 46]. SufSE transfers the sulfur produced by the $\mathrm{CD}$ reaction, following the interaction with the scaffold complex SufBCD, which further enhances the desulfurase activity [47]. SufB has been defined as a scaffold, capable of interacting with SufD and the soluble ATPase SufC [45, 48, 49]. Moreover, this complex uses $\mathrm{FADH}_{2}$ as a redox cofactor [48]. SufD shares substantial sequence similarity with SufB and has been hypothesized to confer iron to the reaction $[50,51]$. The stoichiometry plays an important role in the structural dynamics of the SufBCD complex, with its various oligomeric forms being capable of transferring in vitro the cluster to the receptor proteins $[49,50]$. For in vitro maturation of Fdx, the SufBC 2 D, SufB ${ }_{2} C_{2}$ and $\operatorname{SufC}_{2} \mathrm{D}_{2}$ sub-complexes interact with SufA, which has been proposed to act as a transfer protein for the nascent $\mathrm{Fe}-\mathrm{S}$ cluster [52]. However, it has also been established in vitro that the SufBCD complex is capable of transferring clusters directly to apoproteins without the assistance of SufA [49]. Once the Fe-S cluster is assembled, it is ready to be targeted to the transfer proteins. The SUF system exhibits an A-Type carrier protein termed SufA. [49]. While SufA belongs to the suf operon and IscA to the isc operon, another transfer or carrier protein called ErpA is independent of the $\mathrm{Fe}-\mathrm{S}$ cluster assembly operons [53]. A-type carrier proteins were initially believed to act as alternative scaffolds [31], but several lines of evidence argued against this premise. It was observed that deletions of the type-A carrier produced no phenotypes, probably a reflection of the fact that the nascent cluster can be transferred directly from the scaffold protein [54]. Moreover, the binding capacity of type-A carriers did not allow reversible transfer of the $\mathrm{Fe}-\mathrm{S}$ cluster from the scaffold, and their binding to $\mathrm{CD}$ was not as efficient as that of IscU [55]. For these reasons, two possible roles in Fe-S assembly were considered: they could either act as iron donors [56] or assist the process of transfer to the apoproteins once the $\mathrm{Fe}-\mathrm{S}$ cluster was assembled [49].

Another protein belonging to the SUF system is the $\mathrm{Zn}$ dependent SufU [57], which is absent in the Gram-negative bacteria such as E. coli. SufU, a homolog of IscU, is able to complement SufE, as it happens in the case of Bacillus subtillis, Enterococcus faecalis, Thermatoga maritima and various mycobacteria [58-61].

\section{The NIF system}

The NIF system, initially described in nitrogen-fixing bacterium Azotobacter vinelandii, is a dedicated machinery for the maturation of nitrogenase. Later on, it has also been found co-existing with one or more of the other three $\mathrm{Fe}-\mathrm{S}$ assembly systems in $\varepsilon$-proteobacteria, represented by Helicobacter pylori [62], as well as in the Gram-negative $\gamma$-proteobacteria Dickeya dadantii $[63,64]$ and Klebsiella pneumoniae [65]. The NIF system comprises a CD termed NifS and a scaffold protein NifU. NifU is a functional homolog of the scaffold protein IscU, yet it exhibits some remarkable differences. On its $\mathrm{N}$-terminus it bears cysteines intended for $[2 \mathrm{Fe}-2 \mathrm{~S}]$ cluster binding, while other cysteines found in its middle and its $\mathrm{C}$-terminus seem to bind $\mathrm{Fe}-\mathrm{S}$ clusters in a non-transient manner [66]. NifB is an S-adenosylmethionine (SAM)-dependent enzyme involved in the formation of an $\mathrm{Fe}-\mathrm{S}$ cluster precursor of an iron-molybdenum cofactor (FeMo-co) required for the reconstitution of active nitrogenase [67]. Other proteins involved in the NIF system are Isc $\mathrm{A}^{\text {nif }}$, which likely functions as a scaffold for target apoproteins [32], and a $O$-acetylserine synthase denoted as CysE1, whose activity has been proposed to increment the cysteine pool for the $\mathrm{Fe}-\mathrm{S}$ assembly of nitrogenase [68].

\section{The CSD system}

The CD of the CSD system is encoded by the $\operatorname{cs} d A$ gene. It differs from SufA by substrate specificity, although both proteins share substantial sequence similarity. CsdA is capable of transferring sulfur from L-selenocysteine, L-selenocystine, L-cysteine, L-cystine and cysteine sulfinate [69]. $\mathrm{CsdE}$, a homolog of SufE, catalyzes the release of $\mathrm{Se}, \mathrm{SO}_{2}$ and $\mathrm{S}$ from L-selenocysteine (the most preferred substrate), L-cysteine sulfinate and L-cysteine (the least preferred substrate) $[70,71]$. Regardless of the CD activity observed in vitro for each pure protein, labeling assays confirmed that CsdA and CsdE may enhance each other's activity twofold [11, 72]. In E. coli, the CsdAE complex has been observed in unison with the SufSE and SufBCD sub-complexes. Under specific nutritional deficiency stress, the CsdAE complex may also recruit CsdL, an E1-like protein found in ubiquitinlike systems [73].

\section{Eukaryotic systems}

Eukaryotic cells exhibit the ISC system in the mitochondria and the CIA pathway in the cytosol. The photosynthetic eukaryotes also carry the SUF system in their plastids [74]. Moreover, the SUF system has been retained even in the non-photosynthetic apicoplast of the apicomplexan parasites $[74,75]$, as well as in the cytosol of some parasitic and commensal amitochondriate protists [23]. Finally, the NIF system is rarely present in the mitochondria and cytosol (e.g., in Entamoeba histolytica and Mastigamoeba balamuthi) [76, 77], while parts of the CSD system were found scattered in some parasitic protozoan genomes [78].

\section{The mitochondrial ISC system}

The best-studied mitochondrial ISC systems are those of yeast, plants and mammalian cells. In this section, we will 
base our description on the human model and therefore use the nomenclature for the human ISC Fe-S cluster assembly, unless indicated otherwise. The ISC system from bacteria and eukaryotes exhibits the same general functional traits, such as the sulfur acquisition from a donor cysteine and the assembly of a nascent $\mathrm{Fe}-\mathrm{S}$ cluster on a scaffold protein, with the subsequent transfer to carrier proteins, which will in turn deliver the cluster to apoproteins. However, there are some important differences between the prokaryotic and eukaryotic ISCs. One of them is the ISD11 protein, exclusive for eukaryotes [79]. ISD11 is a small accessory protein that acts in concert with NFS1 [80-83], the scaffold protein ISU2 and the acyl carrier protein ACP [84]. Within the NFS1-ISD11-ACP tripartite complex, ISD11 forms a dimeric association at its core, with ACP occupying a hydrophobic pocket in each ISD11 monomer that stabilizes the complex $[85,86]$. The complex also binds to the scaffold protein ISCU2 and to ferredoxin (FDX2) [87], which acts as an electron donor aided by a ferredoxin reductase (FDXR) [88-90]. ISCU2 is the product of alternative splicing of ISCU which also gives origin to ISCU1, also suggested to play a role in the repair of the $[4 \mathrm{Fe}-4 \mathrm{~S}]$ clusters in the cytosol [91]. In humans, the binding is facilitated by the interaction with a chaperone/co-chaperone complex formed by HSPA9 (also called GRP75 or PBP74) and HSC20 (or HSCB) $[92,93]$, while in yeast this role is performed by mitochondrial Hsp70 protein, ATP-dependent Ssq1 and cochaperone Jac1 [94, 95]. Frataxin (FXN) has been proposed to donate $\mathrm{Fe}^{2+}$ for the reaction and/or act as an allosteric regulator of NFS1, stimulating its activity [96-98]. Moreover, FXN has also been suggested to bind to the chaperone-ISCU2 complex [88]. The binding of ISCU2 to the L(I) YR motif seems essential for the transfer of the cluster to a specific recipient apoprotein [95]. Studies using succinate dehydrogenase complex (SDH) subunits in mammalian cells demonstrate that the clusters are transferred directly from the chaperone complex to the subunits of SDH, achieving their maturation in this step; a similar result was observed for respiratory complexes I and III [95]. Also a monothiol glutaredoxin, GLRX5, has been observed to interact with HSC20, through binding to the same group of cysteines that the chaperone uses to bind SDH [95]. Hence, GLRX5 must be released from the chaperone complex for it to bind to the recipient respiratory complex unit. Consequently, it was proposed that GLRX5 acts as an alternative scaffold for delivery of the $\mathrm{Fe}-\mathrm{S}$ clusters to apoproteins [95].

An alternative model for the transfer of the cluster from the NFS1-ISD11-ACP-ISC2-FXN complex involves an interaction with GLRX5. This model implies that GLRX5 requires a chaperone-assisted transfer of the $\mathrm{Fe}-\mathrm{S}$ cluster from the scaffold complex, which for most apoproteins cannot be bypassed [90]. Mechanistic data for this model have been obtained from the NMR spectra where the
NFS1-ISD11-ISCU complex, aided by the chaperone complex is capable of transferring Fe-S clusters, although these experiments were performed in the absence of GLRX5 [99]. Another piece of evidence to support this model comes from in vitro experiments where GRX5 is capable of interaction with transfer proteins ISCA1 and ISC2, and also mobilizes their [2Fe-2S] clusters [100]. Co-immunoprecipitations of GLRX5 in mice N2a and HeLa cells also detected an interaction with carrier proteins ISCU2 and IBA57 [89]. Moreover, deletion of GRLX5 in humans is known to cause severe microcytic-hypochromic anemia, related to $\mathrm{Fe}-\mathrm{S}$ cluster biogenesis defects [101]. Regardless, the model involving GLRX5 also correlates with the formation and transfer of the $[4 \mathrm{Fe}-4 \mathrm{~S}]$ clusters (discussed in detail below), as the ISD11-ISC2-HSC20-HSC9 complex may only answer for the assembly of $[2 \mathrm{Fe}-2 \mathrm{~S}]$ clusters into the respiratory complexes I through III [90].

The LYR-based transfer model described in human cells differs from the one proposed and demonstrated for yeast mitochondria [102]. We understand these two models are complementary, but we intentionally describe them separately, as they rely on different experimental setups. In yeast mitochondria, the chaperone Ssq1 binds to monothiol glutaredoxin Grx 5 prior to binding to the scaffold protein Isu1, making use of two different binding sites for each protein [102]. The binding of Ssq1 to Grx5 is ATP independent, which entails that the ATP-dependent stage of Ssq1 activity takes place in the reaction upstream, while binding to the co-chaperone Jac1 (Fig. 1). Jac1 is then released from Ssq1 prior to the binding to Grx5, a step that precedes the binding to Isu1. The result is an efficient transfer of the newly formed cluster from Isu1 to Grx5 [102]. The model also implies the release of Grx 5 bound to the cluster from the Ssq1-Isc1 complex, with the concerted activity of exchange nucleotide factor Mge1 [102]. The integration of Mge1 into this model comes from in vitro experiments, in which Mge1 is capable of releasing nucleotides bound to Ssq1 when the chaperone is in contact with Isu1. Therefore, the release of the chaperone from the scaffold (though these experiments where made, in the absence of Grx 5 and in presence of Jac1), allows the continuation of a new cycle of assembly [103]. Mutations in Grx5 in S. cerevisiae trigger a severe phenotype of iron accumulation and subsequent defects in the $\mathrm{Fe}-\mathrm{S}$ cluster-bearing proteins [104]. The interaction of Grx5 with the Isa1 and Isa 2 proteins has also been documented in the fission yeast Schizosaccharomyces pombe [105]. A yeast two-hybrid system provided additional evidence for the interaction between Grx5 and Isa1 in S. cerevisiae [106].

ISCA1 and ISCA2, along with IBA57, form the so-called ISA complex that has been proposed to act as a scaffold involved in the assembly of [ $4 \mathrm{Fe}-4 \mathrm{~S}]$ clusters into a range of mitochondrial proteins, including lipoic acid synthase [89, 107]. Depletion of ISCA1 and ISCA2 in HeLa cells resulted 


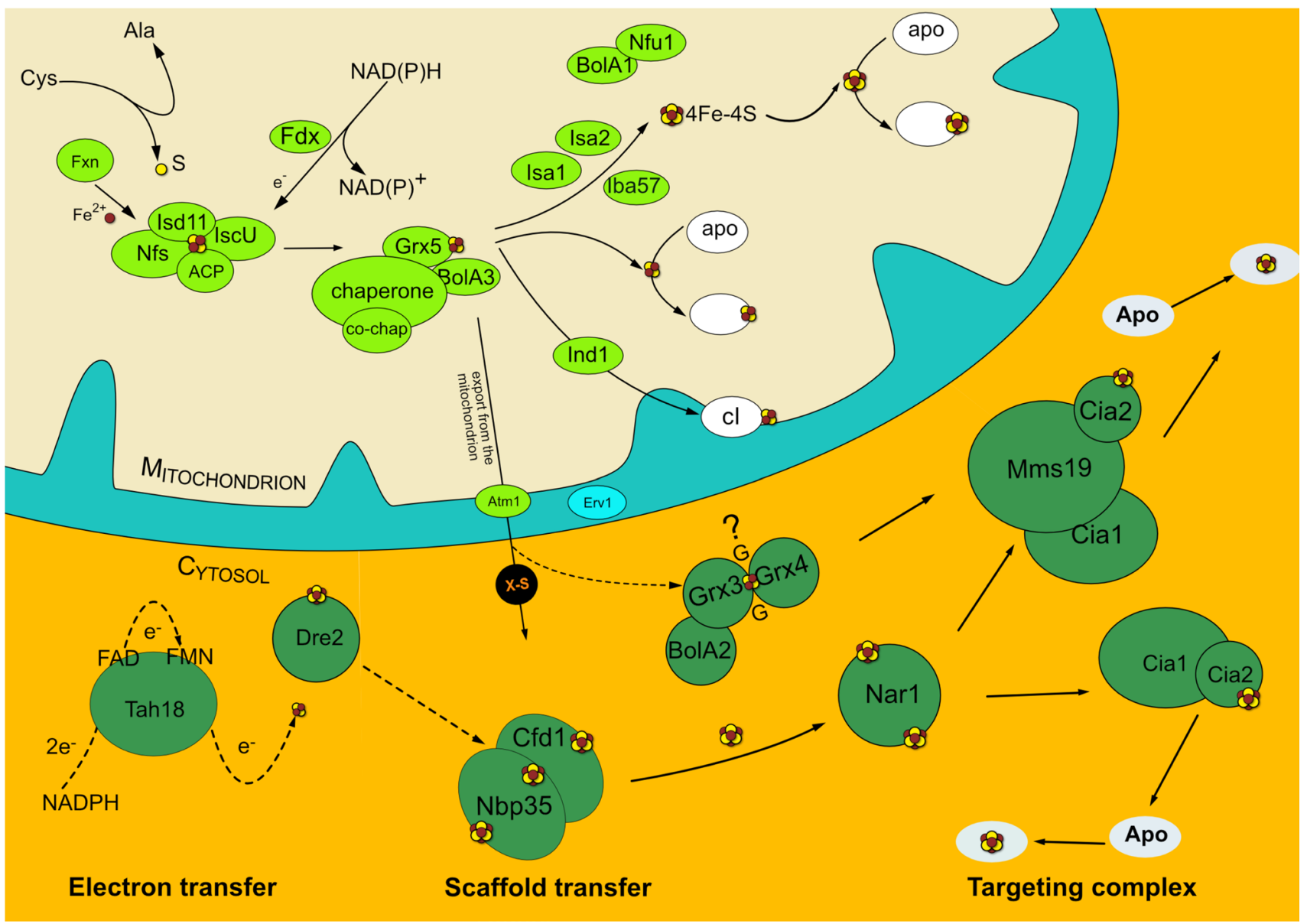

Fig. 1 Schematic representation of the ISC and CIA pathways in eukaryotic cells. The generic representation displays ISC components (in light green) and CIA components (in dark green). Recipi-

in defects in the mitochondrial cristae formation, ultrastructure alterations and acidification of the growth media, which associates these proteins with the maturation of respiratory complexes and hence metabolic defects [107]. However, in mouse cell lines, silencing of these proteins did not cause any morphological alterations, yet respiration measurements corroborated the metabolic defects [89]. Silencing of IBA57 failed to exert an effect on the activity of the Fe-S cluster-carrying mitochondrial aconitase, yet it decreased in the activity of SDH. Similarly, the depletion of ISCA1, ISCA2 and IBA57 significantly lowered the activities of pyruvate dehydrogenase, 2-oxoglutarate dehydrogenase, mitochondrial aconitase, the Rieske protein and other Fe-S cluster-containing mitochondrial proteins. The phenotype could be reversed by RNAi-resistant ectopic expression of the two transfer proteins, proving their involvement in the phenotype [107]. However, [2Fe-2S] ferrochelatase was unaffected by silencing of ISCU1 in mouse, and of ISCU1, ISCU2 and IBA57 in human cells, corroborating their role only in late-acting stages of the Fe-S cluster assembly ent proteins are depicted in white for ISC and blue for CIA. The CIA components reflect the complexes described for the mammalian cell model

[89, 107]. Interestingly, when ISCU2 alone was silenced, increased amount of ISCU1 was observed in HeLa cells and vice versa, which led to the suggestion that these proteins may have redundant functions [107]. This is in partial agreement with human cases of leukodystrophy and hyperglycemia associated with defects in ISCA2 accompanied by a reduction in $[4 \mathrm{Fe}-4 \mathrm{~S}]$ clusters in respiratory complexes II and IV [108]. Alternatively, overexpression of ISC2 in an ISCU1 knock-down background in mouse cells showed that ISCA1, but not ISCA2, was essential for the [4Fe-4S] cluster assembly, since ISCU2 could not rescue the [4Fe-4S] defect caused by silencing of ISCU1 [89]. Regardless, the two scaffold proteins in mouse and human interact with each other in vitro $[89,109]$, although only ISCU2 was able to bind IBA57 [89].

The counterparts of human ISCU1 and ISCU2 in yeast are Isa1 and Isa2, which also function as scaffold proteins [110-112]. Experiments replacing Isu1 with bacterial A-type proteins in an IsuI mutant background corroborated that this protein, and not Isu2, is the functional ortholog of 
the bacterial counterpart [111]. Notably, Isu1 and Isu2 interact unlike their counterparts in humans [111]. Silencing of Isu1, Isu2 and Iba57 disrupts the activities of mitochondrial aconitase, biotin synthase and lipoic acid synthase, just like in human cells [110, 111, 113]. Regardless of whether Isu1, Isu 2 and Iba57 are indeed directly involved in the [2Fe-2S] cluster assembly in both humans and yeast [100, 109, 114], there is a consensus that they all are late-acting components in the $\mathrm{Fe}-\mathrm{S}$ assembly, directly involved in $[4 \mathrm{Fe}-4 \mathrm{~S}]$ cluster formation [115].

Another protein related to the $\mathrm{Fe}-\mathrm{S}$ cluster assembly and mitochondrial respiratory complexes is the P-loop ATPase IND1. Silencing of IND1 caused a severe decrease of the Fe-S cluster-carrying complex I subunits, namely NDUFS 1, NDUFV1, NDUFS3 and NDUFA13, leading to a defect in the assembly of the peripheral arm of the complex [116]. Depletion of Ind 1 in the yeast Yarrowia lipolytica also causes a defect in complex I assembly [117].

The transfer of the $\mathrm{Fe}-\mathrm{S}$ clusters to apoproteins involves the mobilization of the recently formed cluster to transfer proteins or assembly factors (called carrier proteins in bacteria), which will subsequently pass on the cluster to the recipient protein. In bacteria, this process has been defined to work in a "one-way" mode, i.e., is irreversible [19, 49]. The transfer protein NFU1 (or Nfu in yeast) is known to form homodimers and functions in mitochondria, cytosol and plastids [118-122], although in vitro experiments of the bacterial protein in A. vinelandii has been recorded forming heteromers [123]. The exact role of NFU1 in humans remains unclear, although defects in NFU1 have been related to multiple mitochondria dysfunction syndrome [124-126]. In this syndrome, the lack of lipoic acid, due to the defective activity of lipoic synthase, causes the subsequent impairment in lipoid acid-dependent enzymes, such as PDH and $\mathrm{KDH}$ [126]. In vitro assays have determined that the protein interacts with ISCA1 [89] and BOL3 in humans [127]. Similar assays performed with yeast Nfu detected associations with Isa1 and Isa2, as well as with the [4Fe-4S] cluster proteins, Aco1, Aco2, lipoic synthase, biotin synthase and homoaconitase (Lys4) [120]. Yeast cells defective in Nfu displayed a relatively mild respiration impairment [120]. Yeast triple mutant bola1-bola3-nfu exhibited an enhanced phenotype unlike any of the individual mutants. Complementation experiments using human NFU1 or BOLA1 partially recovered the phenotype of the mutant, but not BOLA3, which indicates that a concerted activity of NFU1 and BOLA3 is necessary to recover the phenotype [120]. Moreover, the overexpression of Nfu in a bola3 mutant recovered the respiratory defect phenotype, which indicates overlapping functions [120].

The obvious connection between Nfu and BolA assembly factors places them in similar, yet non-overlapping roles. BolA is a recently described protein of bacterial origin with three homologs in humans [128]. Yeast BolA1 and BolA3 localize to the mitochondria, while BolA2 is present in the cytosol [127]. BolA1 and BolA3 were shown to physically interact in vitro with human proteins NFU1 and GLRX5, respectively, providing further evidence that these proteins fulfill different functions. Indeed, bolal and bola 3 mutants exhibit no growth phenotype, but the double bolal-bola 3 mutant displays a mild respiratory defect associated with decreased activities of enzymes related to the product of lipoic acid synthase, all of which require $4 \mathrm{Fe}-4 \mathrm{~S}$ clusters [127]. Previous findings in yeast regarding BolA2 indicate that this cytosolic protein interacts with Grx3/4 as a chaperone [129].

A very important finding that defined the extent of the mitochondrial $\mathrm{Fe}-\mathrm{S}$ assembly machinery was that of Atm1. A mutant strain for a mitochondrial $\mathrm{ABC}$ transporter in yeast exhibited iron accumulation in mitochondria, respiration defects and increased concentrations of glutathione [130]. Labeled iron assays in a mutant for Atm1 indicated that this protein did not affect the assembly of $\mathrm{Fe}-\mathrm{S}$ clusters in mitochondria, yet it decreased the levels of the Fe-S cluster protein Leu1 in cytosol [131]. The transporter is located in the inner mitochondrial membrane, with its $\mathrm{ABC}$ domains facing the mitochondrial matrix, which implies an export activity mode [132]. This transporter likely transfers a sulfur derivative compound across the mitochondrial membrane, which is essential in cytosol.

\section{The CIA pathway}

Impairment of the mitochondrial $\mathrm{Fe}-\mathrm{S}$ cluster assembly affects maturation of the $\mathrm{Fe}-\mathrm{S}$ proteins in the cytosol of yeast and humans [133]. Indeed, the mitochondrial machinery is involved in the formation of a glutathione-based compound that is translocated to the cytosol to be integrated into the cytosolic $\mathrm{Fe}-\mathrm{S}$ cluster assembly through the $\mathrm{ABC}$ transporter Atm1 (Fig. 1) [131, 134, 135]. The maturation of the $\mathrm{Fe}-\mathrm{S}$ cluster proteins in the cytosol is performed by a different machinery from that of the ISC system that depends on substrates that must be exported out of the mitochondrion.

The cytosolic and nuclear de novo formation of [4Fe-4S] $\mathrm{Fe}-\mathrm{S}$ clusters requires the heterodimeric association of proteins Cfd 1 and Nbp35, which share significant sequence similarity [136-138]. The latter also shares homology with its bacterial and archaeal counterpart $\mathrm{ApbC}$, both being classified as P-loop-containing nucleoside triphosphate hydrolases [139]. The ApbC/Nbp35 proteins were the first $\mathrm{Fe}-\mathrm{S}$ cluster assembly proteins described in the Archaea [139]. Nbp35 exhibits an N-terminal Fdx-like domain, an ATP-binding motif and C-terminal cysteine residues [139]. The formation of the stable heterodimer depends on a shared [4Fe-4S] $\mathrm{C}$-terminal cluster, labeled as bridging cluster, while both $\mathrm{Nbp} 35$ and $\mathrm{Cfd} 1$ each bear another [4Fe-4S] cluster in their 
$\mathrm{N}$-termini $[137,140]$ (Fig. 1). Of importance is the fact that the N-terminal $\mathrm{Fe}-\mathrm{S}$ cluster of Nbp35 is oxygen stable, unlike the bridging cluster [138, 140, 141]. Consequently, the $\mathrm{N}$-terminal truncations render the protein unable to bear a cluster [137]. The Cfd1-Nbp35 conformation results in a heterotetrameric association capable of functioning as a scaffold for the assembly of an Fe-S cluster [140]. Remarkably, Cfd 1 and Nbp35 are not targets of the de novo assembly factors of the CIA pathway, despite the fact that they themselves carry clusters. Their assembly and insertion depend on the early steps of the pathway [138]. Importantly, the Cfd1-Nbp35 heterotetramer formation does not take place in plants and certain anaerobic protists due to the absence of Cfd1 from their genomes [142, 143]. In humans, ablation of NBP35 causes an impairment in the iron-regulatory protein IRP1, which in turn affects the levels of ferritin and increases the levels of transferrin uptake by a concomitant increase of transferrin receptor levels in the cell. This effect on iron homeostasis involves the CIA machinery in a regulation role in mammals that is not observed in yeast [141].

The answer to which factors feed the stable Fe-S clusters to the scaffold protein Nbp35 came about with the characterization of Dre2 in yeast [144]. The deletion of Dre2 was lethal when combined with those of the mitochondrial carrier proteins Mrs3 and Mrs4 under iron-depleted conditions. The rationale behind this experiment was to identify protein(s) that provide a compound(s) for the cytosolic $\mathrm{Fe}-\mathrm{S}$ cluster assembly, and resemble the phenotypes of CIA protein mutants known at the time [145]. Interestingly, although described as a cytosolic protein, low amount of Dre2 was also found either in the mitochondria and/or bound to the cytosolic side of the outer mitochondrial membrane [145, 146]. Dre2 is the yeast counterpart of anamorsin (or CIAPIN1, cytokine-induced apoptosis inducer 1) in humans, as proven by a complementation assay in yeast with the human gene [144, 145, 147]. The protein exhibits an $\mathrm{N}$-terminal SAM methyltransferase-like domain, and on its C-terminus two motifs named I and II, which display cysteines required to bind the clusters [148]. In vitro experiments with overexpressed protein show that maturation of Dre2, which bears a $[2 \mathrm{Fe}-2 \mathrm{~S}]$ and a $[4 \mathrm{Fe}-4 \mathrm{~S}]$ cluster, is independent of the CIA factors, but requires the presence of $\mathrm{Nfs} 1$, positioning it functionally upstream of the Cfd1-Nbp35 scaffold step [144, 148]. Further analyses revealed that Dre2 interacts and functions in association with a diflavin reductase Tah18, which transfers electrons from $\mathrm{NADPH}_{2}$ to Dre2 (Fig. 1) [144]. At the same time, the human homolog of Tah18, NDOR, rescues the phenotype of tahl 18 yeast mutants and cooperates with Dre2, which further strengthens the relationship between Dre2 and Tah18 [144]. However, in this model Dre2 is incapable of transferring clusters to apoproteins, but seems indirectly involved, together with Tah 18 , in the transfer of electrons for the formation of the $[4 \mathrm{Fe}-4 \mathrm{~S}] \mathrm{N}$-terminal cluster of Nbp35, yet has no effect on Cfd1 [144]. In human cells, CIAPIN1 has been found to interact with GLRX3, a cytosolic monothiol glutaredoxin [129, 147, 149] described below. Indeed, in vitro assays captured the transfer of a [2Fe-2S] cluster from the N-terminus of GLRX3 to the $\mathrm{N}$-terminus of CIAPIN1. This result led to propose that the glutaredoxin feeds the [2Fe-S] cluster to CIAPIN1 [149]. However, this observation is in disagreement with the previously mentioned results from yeast, where the C-terminus of Dre2 is key for cluster binding [144]. Another piece of evidence postulates that the maturation of the $[2 \mathrm{Fe}-\mathrm{S}]$ cluster in CIAPIN1 is not dependent on GLRX3, regardless of their physical interaction [129].

The transient assembly of the $\mathrm{Fe}-\mathrm{S}$ cluster on the Cfd1-Nbp35 scaffold is followed by the interaction of the heterotetrameric complex with the iron-only dehydrogenase Nar1, which receives the cluster to further pass it on to the targeting complex that will install the cluster into the apotargets [133]. Nar1 also bears an Fdx-like domain on its $\mathrm{N}$-terminus and a cysteine domain on its $\mathrm{C}$-terminus typical of iron-only hydrogenases (for binding of the H-cluster). Since Nar1 is itself an Fe-S cluster protein, its maturation depends on its association with the Cfd1-Nbp35 complex [133].

The following proteins constitute the CIA targeting complex in humans: the WD-40-type protein CIA1 (also called CIAO), which functions as a scaffold; MMS19 (Met18 in yeast), CIA2A (or FAM96A) and CIA2B (or FAM96B), whose role is targeting recipient apoproteins [15, 150-153]. The cytosolic iron-sulfur protein 1 (CIA1) belongs to the family of WD-40 proteins, which are known for their $\beta$-propeller structure repeats [150]. It was initially characterized in yeast, where its depletion affected the maturation of the cytosolic and nuclear $\mathrm{Fe}-\mathrm{S}$ proteins, yet it had no impact on the levels of Nbp35. Moreover, Cia1 was found to interact with Nar1, the iron-only hydrogenase that receives the clusters from the Cfd1-Nbp35 scaffold. Similarly, ${ }^{55} \mathrm{Fe}$ incorporation in the Cial mutant affected apoproteins, such as Leu1 and Rli1, but had no significant impact on Nbp35, Nar1 and mitochondrial $\mathrm{Fe}-\mathrm{S}$ proteins [150]. Complementation assays of the Cial mutant with the human CIAO protein recovered the phenotype, confirming their functional redundancy. Moreover, a structural analysis of Cial determined that it exhibits a conserved propeller axis structure [154]. Hence, it was concluded that in the maturation of cytosolic $\mathrm{Fe}-\mathrm{S}$ cluster proteins, Cia1 performs a role downstream of Nar1 [16].

MMS19 was initially discovered in yeast, in mutants with an increased sensitivity to methyl methasulfonate, as reflected by its name [155]. ${ }^{55} \mathrm{Fe}$ incorporation in cells depleted for Mms19 affected apoproteins in a fashion similar to that described for the Cia1 mutant [151]. Importantly, the downregulation of MMS19 influenced proteins involved in 
the DNA metabolism, such as Rad3 helicase and XPD. In line with this finding, DNA helicase Dna2 and Rli1 were found interacting with MMS19, and the same applies to components of the CIA complex, namely CIA1, CIA2A and CIA2B $[151,152,156]$. Combined, these results provide evidence for the role of MMS19 downstream of CIA1, targeting a specific set of proteins, many of which are involved in DNA maintenance [151, 152].

Further characterization of proteins that were found to interact with MMS19 revealed their involvement in the late stages of the CIA pathway. Interestingly, CIA2A and CIA2B were found to interact in a mutually exclusive fashion with CIA1 [15]. Specific associations of these proteins seem to be necessary for the maturation of certain proteins. CIA2A is directly involved in the maturation of IRP1, which plays a role in cellular iron homeostasis [157]. CIA2B in association with CIA1 and MMS19 is responsible for the assembly of the $\mathrm{Fe}-\mathrm{S}$ cluster of DYPD, an enzyme involved in the detoxification of pyrimidine derivatives [15]. Moreover, for the maturation of GPAT, an enzyme of the purine nucleotide synthesis pathway, and POLD, only CIA1 and CIA2B were required $[15,153]$.

MMS19 exhibits nine HEAT repeats, known to facilitate protein-protein interactions, which are distributed throughout the whole protein [153]. Mutations in the C-terminal HEAT repeats of MMS19 prove that they are responsible for the binding of CIA2B. Moreover, the absence of MMS19 renders CIA2B subject to proteosomal degradation [153]. Since the binding of CIA2B to MMS19 was often accompanied by the presence of CIA1, it was proposed that at least two distinct types of associations, namely CIA1-CIA2A and CIA1-MMS19-CIA2B, perform the maturation of different subsets of proteins (Fig. 1). In this model, CIA1 with CIA2A act in an iron-regulation/sensing role, as depicted by their specific interaction with IRP1 and IRP2, whereas CIA1 with MMS19 and CIA2B supply DNA metabolismrelated proteins [15].

\section{Iron sensing and regulation and the relationship with the $\mathrm{CIA}$ pathway}

Iron sensing as a regulatory mechanism differs between mammals and yeast. In mammals, the iron-responsive protein 1 (IRP1) exhibits aconitase activity when bound to $\mathrm{Fe}-\mathrm{S}$ clusters; once the cluster is lost, IRP binds to iron-responsive elements on mRNAs that specify proteins known to regulate iron homeostasis [157]. In yeast, aconitase does not exhibit mRNA binding activity. However, two important players related to the cytosolic $\mathrm{Fe}-\mathrm{S}$ cluster assembly and iron homeostasis are the Grx3/4 proteins. They affect CIA proteins, their target apoproteins and some mitochondrial $\mathrm{Fe}-\mathrm{S}$ assembly proteins, and therefore their involvement in cytosolic and mitochondrial iron homeostasis [158]. Yeast mutants Grx3/4 exhibit reduced activities of respiratory complexes II and IV, as well as those of the mitochondrial ISC assembly scaffold proteins Aco1, Leu1 and Isu1. Moreover, the mutants display up to tenfold decrease of iron incorporation into the CIA components that themselves carry Fe-S clusters, namely Dre2, Nar1 and their target protein Rli1, and the same applies for Isu1, biotin synthase, dihydroxyacid dehydratase and heme-containing catalase $[158,159]$. These results point to an overall effect on iron supply, which was markedly more severe in the cytosol than in the mitochondria [158].

The regulation of iron concentration in yeast is directed by the transcription factors Aft 1 and Aft2, which manage the transport of iron into the cell [160]. In iron-replete conditions, Aft1 is a cytosolic protein, yet when iron concentration is low, it is mobilized to the nucleus, where it activates the transcription of the iron regulon [160-162]. It has been suggested that this activation is incited by the failure of the mitochondrial iron supply directed toward the Fe-S cluster assembly, yet the deletion of components of the CIA pathway does not induce the same response $[163,164]$. Mutants that activate the iron regulon by stimulating the activity of the high-affinity iron transport system of multicopper oxidase Fet 3 led to the discovery of six proteins involved in this role $[160,165]$. These are Nfs1, Isu1, Gsh2 [130], mitochondrial carrier Mtm1, an interactor of the multiprotein regulator complex (which in turns regulates RNA polymerase II), Sin4, [166] and Fra1 (Fe repressor of activation-1), the yeast homolog of bacterial BolA [165]. These findings confirm earlier observations, in which the deletion of Grx3 and Grx4 induced the iron regulon when iron concentrations were normal [161, 162]. Fra1 interacts with Fra2, Grx3 and Grx4, interactions that took place regardless of the iron conditions in which the cells were maintained [167]. It was also described that Grx3 and Grx4 interact with Aft1 [161]. Deletion of the gene fral does not specifically activate the iron regulon, while that of fra 2 does [165]. Fra2 binds Grx 3 through a specific interaction mediated via a histidine residue, which is critical for modulation of the iron regulon via Aft1 [168]. Based on this finding, Fra1 and Fra2 seem to interpret the iron conditions of the $\mathrm{Fe}-\mathrm{S}$ cluster assembly. They are related to mitochondrial $\mathrm{Fe}-\mathrm{S}$ cluster assembly and the iron regulon is induced when their concentration decreases [165].

In humans, only GLRX3 (also called PICOT) is found in the cytosol where it interacts with the cytosolic form of the BOLA family in humans, BOLA2 [129, 169]. This interaction is iron concentration dependent. Moreover, mutation of the GLRX3 cysteines in the motifs GrxA and $\mathrm{GrxB}$, which are involved in binding of the $[2 \mathrm{Fe}-2 \mathrm{~S}] \mathrm{Fe}-\mathrm{S}$ cluster, almost completely disrupts the interaction with BOLA2 [129]. 


\section{Fe-S clusters in the supergroup Excavata}

\section{Euglenozoa}

Excavata is a eukaryotic "supergroup" that brings together a diverse array of protists $[8,170,171]$, with just a few studied so far from the perspective of the $\mathrm{Fe}-\mathrm{S}$ cluster assembly. The best-described one is that of the kinetoplastid flagellates, which are responsible for a range of diseases in humans and other vertebrates [172]. The only information available for the other two euglenozoan clades, the euglenids and diplonemids, can be derived from their genomes which are, however, not yet publicly available. All these protists display a single, usually extensively reticulated, cristae-bearing mitochondrion, with an active and complex electron transport chain. Kinetoplastids that belong to the genera Trypanosoma and Leishmania are capable of aerobic fermentation, as they excrete metabolites from both glucose and amino acid metabolisms, but use $\mathrm{O}_{2}$ as an electron acceptor [173]. Since both these parasitic groups exhibit a classical cytosolic Fe-S assembly, from the genomic information available to us we predict that similarly conserved situation occurs in diplonemids and euglenids (our unpubl. data).

The Fe-S cluster assembly was systematically studied only in the model species Trypanosoma brucei, which expresses all components of the ISC and CIA pathways in its mitochondrion and cytosol (Fig. 2) [172, 174]. Upon depletion, most of these proteins are essential for both studied life cycle stages, namely the bloodstream stage found in the blood of mammals and the procyclic stage that is confined to the tsetse fly vector. Moreover, rescues by human homologs or expression of the T. brucei proteins in the corresponding yeast mutants confirmed sequence-based homology predictions [20, 175-185], Tonini et al., resubmitted]. Only FdxB [177], selenocysteine lyase [78] and $\mathrm{TbCia} 2 \mathrm{~A}$ (Tonini et al. 2018, resubmitted) were found to be dispensable for T. brucei. A homolog of the Grx-interacting protein, BolA, has also been detected in the genome of $T$. brucei, although its role and localization have not been studied yet.

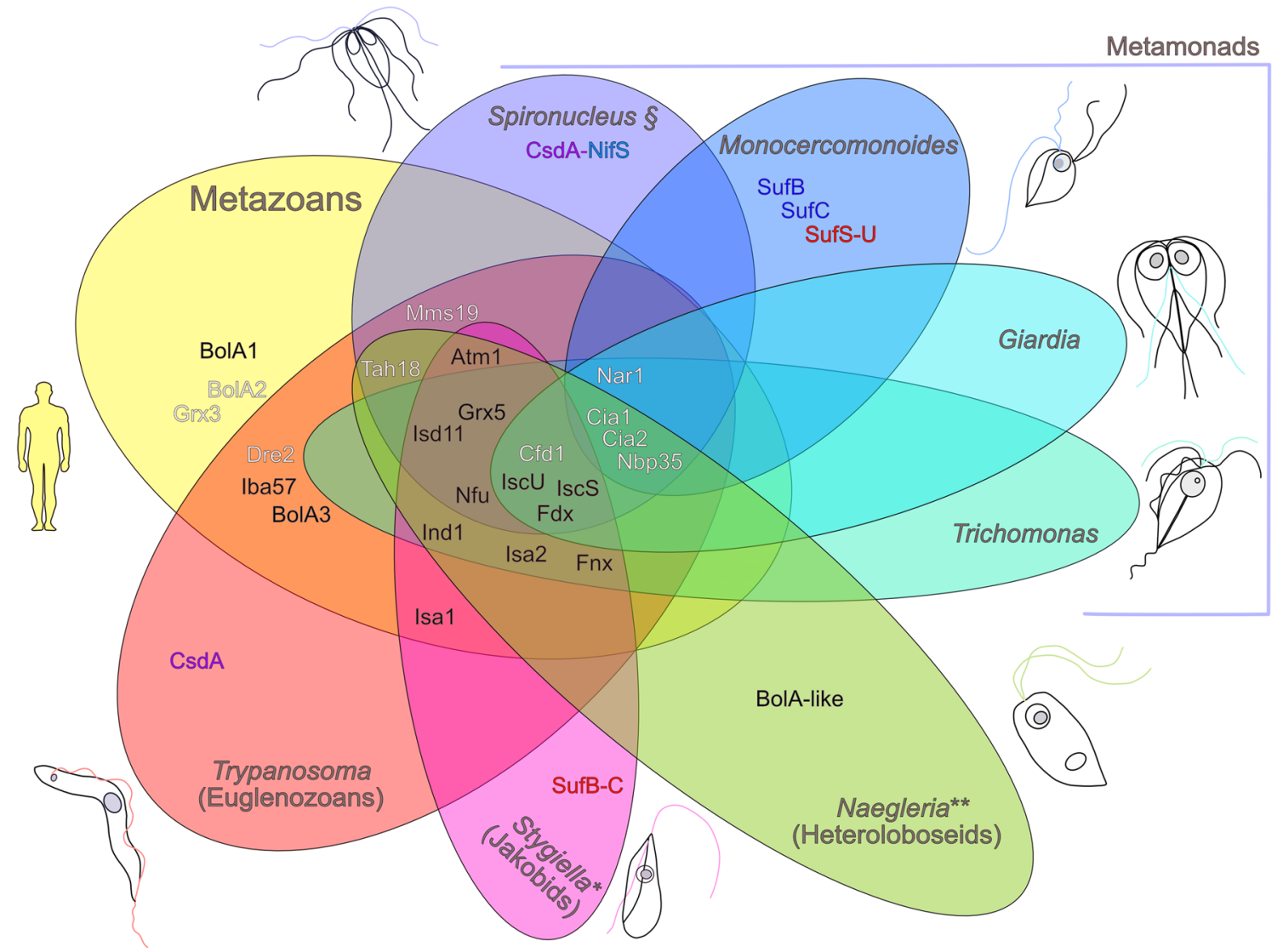

Fig. 2 Distribution of ISC (black letters), CIA (white letters), NIF (light blue letters), CSD (purple letters) and SUF (in dark blue, gene fusions in red) components in metazoans and representative species of Excavata. Representative species denoted in the figure are Stygiella incarcerata*, Naegleria gruberi**, Spironucleus salmonicida§, Monocercomonoides sp., Trichomonas vaginalis and Giardia intestinalis. Data presented here should not be assumed for the whole genera, but only for representative species 
A number of gene duplications likely took place, as several components of this pathway are supernumerary. In particular, Nfu is represented by three paralogs, which are expressed in the mitochondrion and the cytosol in T. bru$c e i$, while four paralogs are found in the related Leishmania spp., although these remain unstudied [185]. Moreover, in $T$. brucei two ferredoxins (FdxA, FdxB) are present and transcribed [177], Mms19 is found in two genomic loci and Cia2 has been duplicated into Cia2A and Cia2B [172] [Tonini et al., resubmitted], just like in humans [15]. The presence of supernumerary components is not unique, since f.e. in the plant Arabidopsis thaliana five Nfu homologs are present in various subcellular compartments [119]. In some instances, the complexity took the path of alternatively spliced versions targeted at different locations, as was described in humans [118]. The finding that all three Nfu proteins are essential for $T$. brucei suggests that they are likely involved in the maturation of different sets of proteins [185].

Several aspects of the $\mathrm{Fe}-\mathrm{S}$ cluster assembly and $\mathrm{Fe}-\mathrm{S}$ cluster-carrying proteins have also been studied in the trypanosomatid parasite Leishmania spp., which unlike $T$. brucei prefers an intracellular niche that requires a range of specific metabolic adaptations [186]. Leishmania seems to use several $\mathrm{Fe}-\mathrm{S}$ clusters containing proteins for redox sensing [187]. Trypanosoma cruzi, T. brucei and Leishmania spp. encode three 1-C-Grx genes in their genomes [188]. Monothiol (1-C-Grx) and dithiol (2-C-Grx) glutaredoxins exhibit distinct active sites motifs, $\mathrm{CxxS}$ and $\mathrm{CxxC}$, respectively, which differentiate them [189]. It has been observed in vitro that in T. brucei three 1-C-Grxs proteins are capable of using glutathione and trypanothione as cofactors in the mitochondrial [2Fe-2S] cluster transfer [190]. This is a striking difference from the system described in yeast, where the glutaredoxin-bearing domain of Grx5 uses glutathione as a sulfur donor [188]. Even more remarkable is the fact that in T. brucei only 1-C-Grx 1 , but not $1-\mathrm{C}-\mathrm{Grx} 2$ and 3 , is capable of partially rescuing the deleterious phenotype of the Grx5 yeast mutant [188]. All other components of the ISC pathway, as well as most proteins known to participate in the CIA pathway, have also been detected in the Leishmania genome [74].

\section{Heteroloboseids}

This clade brings together amoebic, amoeboflagellated and cyst-forming protists found in both oxic and anoxic (or microaerophilic) environments, most of which remain understudied [191]. Approximately, 150 species are known to belong to this clade and, though it is not species rich, this group gathers a high morphological variability and a broad ecological distribution. Some of its members may transit through the flagellated and amoeba life stages, while others have retained either the former or the latter stage [191]. They have been found in a wide range of environmental conditions such as extreme heat, cold, high altitudes, extreme $\mathrm{pH}$ and hypersaline concentrations [192-197]. We know most about the genus Naegleria, as it includes the brain-infecting amoeba $N$. fowlerii, and the related Paravahlkampfia francinae, also responsible for amoebic meningoencephalitis [198]. Both species possess classical mitochondria. On the other hand, a group of heteloboseids, such as Sawyeria marylandensis [199, 200], Psalteriomonas lanterna [201-203], Monopylocystis visvesvarai [199] and Creneis carolina [204], are found mostly in low oxygen conditions and carry the MROs. Other heteroloboseids including the halophilic Pleurostomum flabellatum and Vahlkampfia anaerobica have been described to harbor cristae-devoid mitochondria, although their genomes and metabolisms have not yet been thoroughly studied [193, 205].

Naegleria possesses classical ATP-producing mitochondria and displays components of the ISC pathway IscS, IscU and Isd11, as well as two putative Fdxs, Isa, Grx, Atm1 and a BolA-like protein (Fig. 2). Moreover, the hydrogenosome of Sawyeria marylandensis contains paralogs of IscS and IscU, as well as Fxn and Fdx [200].

\section{Jakobids}

Mitochondrial genomes of jakobids belong to the most bacterial-like genomes known to date, though this premise has been challenged by the plausibility of extensive lateral gene transfer into the mitochondrial genomes [206-208]. Regardless, the organelle of jakobids contains the most gene-rich mitochondrial genomes, with the most extreme case represented by Andalucia godoyi, which displays 66 protein-coding genes and 29 tRNA genes [209]. The organelle of Stygiella incarcerata, originally considered to be a mitochondrion devoid of the cristae, is now known to be a DNA-lacking hydrogenosome [207, 210].

Interestingly, the hydrogenosome of $S$. incarcerata retains a complete $\mathrm{Fe}-\mathrm{S}$ cluster assembly machinery, which includes IscS, IscU, Isa1 and Isa2, Fxn, Fdx, Grx5, Ssq1 chaperone and Nfu (Fig. 2, Table 1) [210]. The ABC transporter Atm1 is also expressed, suggesting this organism displays a mitochondrion-dependent, cytosol-localized $\mathrm{Fe}-\mathrm{S}$ cluster assembly. At the same time, a SufCB fusion seems to lack the mitochondrial targeting signal, implying its highly likely cytosolic localization [210]. However, it has been documented in other MRO-bearing organisms such as Blastocystis, Entamoeba and Trichomonas that the hydrogenosomal proteins may not require a dedicated targeting signal to be translocated into the organelle [28, 211-213]. The assembly of SufBCD in bacteria studied both in vitro and in vivo demonstrated its role in the maturation of $[2 \mathrm{Fe}-2 \mathrm{~S}] \mathrm{Fdx}$, aided by SufA in the transfer of the cluster [48-50]. The SufCB fusion, most likely obtained from bacteria, has been 
Table 1 Presence/absence of ISC, CIA, SUF, NIF and CSD components in different excavates and breviate Pygsuia

\begin{tabular}{|c|c|c|c|c|c|c|c|c|c|c|c|}
\hline & Organism & T. brucei & L.donovani & Naegleria & Sawyeria ${ }^{\mathrm{a}}$ & Stygiella ${ }^{\mathrm{a}}$ & Giardia $^{\mathrm{a}}$ & Spironucleus $^{\mathrm{a}}$ & Trichomonas $^{\mathrm{a}}$ & $\begin{array}{l}\text { Monocer- } \\
\text { como- }^{\mathrm{a}} \\
\text { noides }^{\mathrm{a}}\end{array}$ & Pygsuia \\
\hline \multirow[t]{11}{*}{ ISC } & IscS & $\checkmark$ & $\checkmark$ & $\checkmark$ & $\checkmark$ & $\checkmark$ & $\checkmark$ & $\checkmark$ & $\checkmark$ & & $\checkmark$ \\
\hline & IscU & $\checkmark$ & $\checkmark$ & $\checkmark$ & $\checkmark$ & $\checkmark$ & $\checkmark$ & $\checkmark$ & $\checkmark$ & & \\
\hline & Isd11 & $\checkmark$ & $\checkmark$ & $\checkmark$ & & $\checkmark$ & & $\checkmark$ & $\checkmark$ & & \\
\hline & Isa1 & $\checkmark$ & & & & $\checkmark$ & & & & & \\
\hline & Isa2 & $\checkmark$ & & & & $\checkmark$ & & & $\checkmark$ & & \\
\hline & $\mathrm{Fdx}$ & $\checkmark$ & $\checkmark$ & $\checkmark$ & $\checkmark$ & $\checkmark$ & $\checkmark$ & $\checkmark$ & $\checkmark$ & & \\
\hline & Fnx & $\checkmark$ & $\checkmark$ & $\checkmark$ & $\checkmark$ & $\checkmark$ & & $\checkmark$ & $\checkmark$ & & \\
\hline & $\mathrm{Nfu}$ & $\checkmark$ & $\checkmark$ & & & $\checkmark$ & $\checkmark$ & $\checkmark$ & $\checkmark$ & & $\checkmark$ \\
\hline & Iba57 & $\checkmark$ & & & & & & & & & \\
\hline & Ind 1 & & & & & $\checkmark$ & & & $\checkmark$ & & $\checkmark$ \\
\hline & Atm1 & $\checkmark$ & $\checkmark$ & $\checkmark$ & & $\checkmark$ & & $\checkmark$ & & & \\
\hline \multirow[t]{8}{*}{ CIA } & Cfd 1 & $\checkmark$ & $\checkmark$ & $\checkmark$ & $?$ & $\checkmark$ & & $?$ & $\checkmark$ & & $\checkmark$ \\
\hline & Nbp35 & $\checkmark$ & $\checkmark$ & $\checkmark$ & $?$ & $?$ & $\checkmark$ & $\checkmark$ & $\checkmark$ & $\checkmark$ & $\checkmark$ \\
\hline & Dre2 & $\checkmark$ & $\checkmark$ & $\checkmark$ & $?$ & $?$ & & $?$ & & & \\
\hline & Tah18 & $\checkmark$ & $\checkmark$ & $\checkmark$ & $?$ & $?$ & & $?$ & & & \\
\hline & Nar1 & $\checkmark$ & $\checkmark$ & & $?$ & $?$ & $\checkmark$ & $\checkmark$ & $?$ & $\checkmark$ & $\checkmark$ \\
\hline & Cial & $\checkmark$ & $\checkmark$ & $\checkmark$ & $?$ & $?$ & $\checkmark$ & $\checkmark$ & $\checkmark$ & $\checkmark$ & $\checkmark$ \\
\hline & $\mathrm{Cia} 2$ & $\checkmark$ & $\checkmark$ & $\checkmark$ & $?$ & $?$ & $\checkmark$ & $\checkmark$ & $\checkmark$ & $\checkmark$ & $\checkmark$ \\
\hline & Mms19 & $\checkmark$ & $\checkmark$ & & $?$ & $?$ & & $?$ & & & $\checkmark$ \\
\hline \multirow[t]{4}{*}{ SUF } & SufS & & & & & & & & & $\checkmark$ & \\
\hline & SufU & & & & & & & & & & \\
\hline & SufB & & & & & $\checkmark$ & & & & $\checkmark$ & $\checkmark$ \\
\hline & SufC & & & & & & & & & $\checkmark$ & \\
\hline NIF & NifS & & & & & & & $\checkmark$ & & & \\
\hline CSD & CsdA & $\checkmark$ & & & & & & & & & \\
\hline
\end{tabular}

${ }^{a}$ The data corresponds to representative species (should not be assumed for the whole genera): Sawyeria marylandensis, Stygiella incarcerata, Giardia intestinalis, Spironucleus salmonicida, Trichomonas vaginalis, Monocercomonoides sp.

$\checkmark$ indicates presence; ? denotes the gene/protein has not been found, but may be present; blank indicates absence

documented only in the cytosol of the anaerobic pathogen Blastocystis [22], in the MRO lumen of Pygsuia biforma [13] and Stygiella [210]. The other bacterial machinery, the NIF pathway, has been observed replacing the ISC system of Entamoeba histolytica [77] and Mastigamoeba balamuthi [76].

\section{Metamonada}

This group consists of anaerobic or microaerophilic protists and is formed by three main lineages: (1) Fornicata (or the diplomonad/retortemonad/carpediemonad clade), represented in this review by the mitosome-bearing Giardia intestinalis and Spironucleus salmonicida [214]; (2) Parabasalia, with the flag species Trichomonas vaginalis, bearer of the first-described hydrogenosome [6]; (3) Preaxostyla, denoted by Monocercomonoides [23] and the free-living Paratrimastix [215]. In all of Excavata, Metamonada exhibits the greatest functional diversity of MROs [28].
Giardia mitosomes lack DNA and are unable to generate or export ATP into the cytosol [5]. Nevertheless, they possess classic ISC components, such as IscS, IscU, Isa, Nfu and Grx [216-221]. Although incomplete, most of the CIA pathway of Giardia is localized in the cytosol, with three homologs of Nbp35 (Nbp35-1, Nbp35-2 and Nbp35-3), while Dre2, Tah18 and Mms19 seem to be absent (Table 1) [143]. Moreover, the ortholog of Cia2 exhibits dual localization in the intermembrane space of the mitosome and the cytosol, while Npb35 seems to be associated with the cytosolic side of the outer mitosomal membrane [143]. It was rather unexpected to find the CIA pathway in a cell lacking Atm1 and its cytosolic interactor, the Tah18/Dre2 complex, as it is widely accepted that the CIA pathway depends on a sulfur-containing molecule transported from the mitochondrial matrix into the cytosol via Atm1. Therefore, it has been hypothesized that the dual localization of $\mathrm{Cia} 2$ aids in the transport of the sulfur-containing molecule necessary for the cytosolic assembly, in the apparent absence of the ABC 
transporter Atm1 [143]. The conspicuous absence of these proteins has also been observed in flagellates where the SUF or the NIF system has replaced the ISC pathway, such as Pygsuia and Blastocystis [13, 22].

Spironucleus salmonicida encodes an unusually high number of cysteine-rich proteins and evolved an extended system for counteracting oxygen stress [214]. This diplomonad exhibits a standard hydrogenosome with a classical MRO-type ISC pathway [222, 223]. All of its components, namely IscS, IscU, Nfu, Fxn, two Fdxs and Jac1, have been localized to the organelle and bear MRO targeting signals [222]. Moreover, a selenocysteine lyase has been detected in this parasite, although neither its expression nor its localization has been confirmed; still, a sequence of a fused selenophosphate synthetase-NifS is present in its genome, similar to the one found in T. brucei $[78,214]$. Putative components of the CIA pathway are also found in the S. salmonicida genome, such as Cfd1, Nbp35, Tah18, Nar1, Cia1, Mms19 and Cia2 (Fig. 2, Table 1).

The human parasite $T$. vaginalis is a microaerophile, which exhibits a very strong iron-regulatable gene expression that allows it to modulate virulence factors and its ability to adapt to microenvironments upon infection [224-227]. Changes in the iron concentrations of its environment result in fold changes in the expression of $\mathrm{Fe}-\mathrm{S}$ clusters assembly components [224, 225]. The DNA-lacking hydrogenosome of T. vaginalis [228] harbors the ISC-type Fe-S cluster assembly and makes use of a supernumerary machinery of components: IscU, two IscS, Isd11s and Fxns, seven [2Fe-2S] Fdxs, three Isa2, four Nfus, four Ind1s (Table 1), as well as two homologs of the chaperone Hsc20 [24, 225, 229-231]. Upon iron depletion, most of these components become upregulated at least twofold. An example of this situation is Fdx, which in this flagellate exhibits six orthologs, of which half is upregulated and half is down-regulated during low iron conditions. This led to the assumption that the expression levels would relate them to their putatively different function, namely a role in the $\mathrm{Fe}-\mathrm{S}$ cluster assembly of the upregulated members, whereas those with low expression are likely involved in metabolic activities [225].

Trichomonas vaginalis is the only member of Excavata and the only other eukaryote apart from Entamoeba histolytica to express a homolog of the bacterial-type iron-sulfur flavoprotein (Isf) [232]. This hydrogenosomal protein is involved in ROS detoxification and protection from the oxygen-rich environmental changes. Moreover, it seems to be present only in methane-synthesizing archaea and bacteria [233, 234]. Isf is able to reduce oxygen and has a detoxifying activity against the drugs metronidazole and chloramphenicol, used to treat anaerobic infections like those caused by $T$. vaginalis [232]. Isf is able to receive in vitro electrons from Fdx and NADH [232]. Like other metamonads, T. vaginalis also lacks the Tah18/Dre2 complex, along with Mms19, while it expresses orthologs of Cfd1, Nbp35, Nar1, Cia1 and Cia2 (Table 1) [143].

Various other metamonads, namely Carpediemonas membranifera, Chilomastix cuspidata, Dysnectes brevis, Ergobibamus cyprinoides, Spironucleus vortens and Trepomonas $P C 1$, for which no complete genomes but expressed sequence tags are available, bear IscS and IscU [28]. Moreover, they all seem to express Nbp35 of the CIA pathway, while Cfd 1 is mostly absent in this group, with the exception of $C$. membranifera and C. cuspidata [143]. Cial was found in all these protists, except $S$. vortens. Like in a range of metamonads, the Tah18/Dre2 complex and Mms19 are absent. However, it has been suggested that the remaining CIA components may be present in the genomes, but missed in the available datasets [143].

Finally, the oxymonad Monocercomonoides, the only genuine "amitochondriate" known so far, is also the most extreme example of the $\mathrm{Fe}-\mathrm{S}$ cluster machinery reduction [23]. With several CIA pathway components complemented by the expression of SufB, SufC and the SufS-U fusion, it is the only known eukaryote that completely lacks the mitochondrial ISC machinery and instead acquired the bacterialtype SUF components. None of these components seem to bear a MRO targeting signal, as they translocate neither into the hydrogenosome of T. vaginalis nor the mitochondria of S. cerevisiae [23]. The CIA pathway components of Monocercomonoides identified so far are Nbp35, Nar1, Cia1 and $\mathrm{Cia} 2 \mathrm{~A}$ and $\mathrm{Cia} 2 \mathrm{~B}$ (Table 1). Its composition implies that the de novo formation of clusters uses the bacterial SufS-U CD-scaffold on SufB and SufC, and was apparently obtained by a lateral gene transfer. This event likely took place before the loss of the mitochondrion in Monocercomonoides, as gathered from its closest relative, Paratrimastix pyriformis, which also possesses homologs of the SUF machinery and bears an MRO [23, 235].

\section{Presence vs functionality: the requirement for mechanistic data to complement phylogenomic analyses}

The expansion of genomic analysis tools has given rise to a high number of publicly available genomes. Studies of the evolution of mitochondria and MROs have unraveled a wide variety of adaptations in the $\mathrm{Fe}-\mathrm{S}$ cluster assembly machineries that could provide explanations for the substantial differences observed even among the model organisms from the supergroup Opisthokonta. The mechanisms behind the presence or absence of components of the ISC, SUF and CIA pathway in these clades, however, are mostly unknown, basically due to lack of mechanistic data.

One of the prevalent differences observed between the few above-mentioned species and the Opisthokonta model 
species is the absence of Isd11 in organisms bearing ISC. This feature points out to an acquisition of IscS/IscU from bacterial lineages. Regardless, in Excavata IscS is always accompanied by IscU, which confirms the findings of several groups on the requirement of the $\mathrm{CD}$ for its specific scaffold to perform desulfuration of cysteine [236]. The presence of Isd11 in T. vaginalis has been suggested as a unique acquisition, from a endosymbiotic event that gave origin to MROs [79]. However, this hypothesis leaves out the fact that the protein is also absent in protists described recently as bearing similar organelles.

The dispersed distribution of the scaffold-type proteins, particularly those characterized as the carrier or transfer proteins, is important for the determination of the mechanistic specificity of the $\mathrm{Fe}-\mathrm{S}$ cluster assembly systems. CsdE is a $\mathrm{CD}$ incapable of complementing the assembly of $\mathrm{Fe}-\mathrm{S}$ clusters on the IscU scaffold, despite the wide range of substrates this CD is able to metabolize [46, 71, 73, 236]. This is, however, not exactly the same for the transfer proteins, which to deliver the clusters also require a physical interaction with their recipient apoproteins. Unlike the CDs with U-type scaffolds, the carrier or transfer proteins seem to be, to a certain extent, interchangeable in bacteria [73]. For example, the deletion of IscA or SufA in E. coli does not affect survival; however, this is not true for the absence of ErpA [237, 238]. A similar situation was observed for $S$. cerevisiae [239]. However, in the presence of oxygen, Azotobacter vinelandii cannot survive mutation of IscA in the presence of oxygen [240]. The distinct phenotypes following the deletions or mutations of carrier proteins in bacteria indicate their functional specificity in vivo $[53,237]$. This means that the recipient proteins that require maturation by specific transfer proteins may or may not be structurally recognized by a given system component [53]. These cellular requirements cannot be bypassed by the apparent overall functional redundancy of the $\mathrm{Fe}-\mathrm{S}$ assembly systems. The case of $P y g$ suia is a notable exception to these observations. Breviate Pygsuia exhibits a SufB-C fusion, yet it also harbors a copy of IscS, with no obvious presence of IscU. Therefore, this fusion scaffold may be capable of providing the structural functionality for IscS. [13].

A scaffold protein that has been conserved throughout evolution is Nbp35. Although the CIA pathway displays the characteristics of a relatively new eukaryotic acquisition, the almost universal presence of this protein conveys how the $\mathrm{Fe}-\mathrm{S}$ cluster assembly can repurpose a pre-existing protein for a new function. On the other hand, the partner of Nbp35, $\mathrm{Cfd} 1$, has a rather patchy distribution in the protist groups. Originally from Archaea, most ApbC homologs in bacteria and archaea lack the Fdx motif present in Nbp35 [139].

Another interesting finding is the gene fusion of various SUF components present in metamonads and jakobids. The SUF system is the most ancient of all Fe-S cluster assembly systems [9]. Its wide distribution among the aerobic and anaerobic organisms led to the proposal that it evolved prior to oxygenation of the biosphere and adopted mechanisms for counteracting oxidizing conditions [241]. Though the SUF and ISC systems coexist in various bacterial lineages, the complementation with SUF components in the absence of specific ISC components has not been possible [242]. It has been well established that in proteobacteria the $\mathrm{Fe}-\mathrm{S}$ cluster assembly by the SUF pathway is highly regulated by protein-protein interactions [55, 236, 243]. A study that reported the complementation of the SUF system of $E$. coli with that of E. faecalis also conveyed that the SUF machinery of the Gram-positive bacteria could replace IscS neither in E. coli nor in A. vinelandii [242]. These features pinpoint to a specificity of activities, which may explain why in the protist systems with the SUF fusions IscS or IscU are absent. The presence of the SUF systems in eukaryotes is documented in plastids, which also lack ISC [244]. However, this system displays functional differences from that of bacteria. The observation that SufB in A. thaliana has an ATPase activity, unlike its counterpart in bacteria, denotes that in eukaryotes the SUF system has acquired unique features [245, 246].

The hypothesis mentioned above gives a mechanistic answer for the characteristic presence of the SUF system in protists. However, there is no explanation as to why the SUF system, rather than the ISC or the NIF systems, was obtained. It has been reported that the relationship between the SUF and ISC systems involves regulation of the complete pathways based on environmental conditions. Such is the case of the SUF operon in E. coli, which is overexpressed on low-iron conditions and oxidative stress, at the same time that the ISC operon is rendered inactive by transcriptional regulation of IscR. In Pseudomonas aeruginosa, IscR regulates cellular iron homeostasis by sensing $\mathrm{Fe}-\mathrm{S}$ concentrations [247]. T. vaginalis is an example of adaptation of the $\mathrm{Fe}-\mathrm{S}$ cluster machinery to match specific cellular requirements. This anaerobic parasite displays supernumerary components of various components of the ISC pathway, which are up- or down-regulated in response to the changing iron concentrations in its environment [225].

Therefore, to characterize the regulatory capacity of a system, one has to determine the expression of its components. However, this type of data may be obtained only by analyzing the $\mathrm{Fe}-\mathrm{S}$ cluster assembly as a whole, a field where microbiologists take the lead when compared with what is known about eukaryotic systems. This should not be confused with analytical methods, which are rich in studies of the Fe-S cluster assembly in Opisthokonta. Still, the limited set of model organisms restricts our overall picture. While it is challenging to establish the methodology for a new eukaryotic model organism, this has to be overcome. The establishment of evolutionary relationships based 
on proven experimental models nicely complements the increasing available genomic data, providing elegant mechanistic explanations for changing phylogenomic models [248, 249].

\section{Closing remarks}

The reduction of mitochondria has seen the relocation of the Fe-S cluster assembly to about elsewhere in the cell or a general replacement of its components with paralogs from diverse proteobacterial lineages. The notion that the ISC has been lost from MROs does not translate into the same fate for the mechanism in question, in this case the $\mathrm{Fe}-\mathrm{S}$ cluster assembly. It translates into an adaptation to maintain the entire mechanism, more than to strictly conserve a given set of genes of certain origin. It will require functional analysis of the pathway in some of the protists mentioned above to define the flexibility and limits of simplification and/or patching of the $\mathrm{Fe}-\mathrm{S}$ cluster assembly, which from all we know is an indispensable component of all extant life.

Acknowledgements We are grateful to Dr. Vladimír Hampl (BIOCEV, Charles University, Prague) for critical reading of the manuscript. We would also like to acknowledge the immense amount of guidance from the reviewers of the final manuscript. Support from the Czech Grant Agency 16-18699S, ERC CZ LL1601, and the ERD Funds, Project OPVVV 16_019/0000759 to JL are kindly acknowledged. This article is based upon work from COST action CA15133, supported by COST (European Cooperation in Science and Technology).

Open Access This article is distributed under the terms of the Creative Commons Attribution 4.0 International License (http://creativeco mmons.org/licenses/by/4.0/), which permits use, duplication, adaptation, distribution and reproduction in any medium or format, as long as you give appropriate credit to the original author(s) and the source, provide a link to the Creative Commons license and indicate if changes were made.

\section{References}

1. Roger AJ, Muñoz-Gómez SA, Kamikawa R (2017) The origin and diversification of mitochondria. Curr Biol 27:R1177-R1192. https://doi.org/10.1016/j.cub.2017.09.015

2. Maguire F, Richards TA (2014) Organelle evolution: a mosaic of "mitochondrial" functions. Curr Biol 24:R518-R520. https:// doi.org/10.1016/j.cub.2014.03.075

3. Lill R (2009) Function and biogenesis of iron-sulphur proteins. Nature 460:831-838. https://doi.org/10.1038/nature08301

4. Verner Z, Basu S, Benz C et al (2015) Malleable mitochondrion of Trypanosoma brucei. Int Rev Cell Mol Biol 315:73-151. https ://doi.org/10.1016/bs.ircmb.2014.11.001

5. Müller M, Mentel M, van Hellemond JJ et al (2012) Biochemistry and evolution of anaerobic energy metabolism in eukaryotes. Microbiol Mol Biol Rev 76:444-495. https://doi.org/10.1128/ MMBR.05024-11

6. Müller M (1993) The hydrogenosome. J Gen Microbiol 139:2879-2889
7. Lill R, Kispal G (2000) Maturation of cellular Fe-S proteins: an essential function of mitochondria. Trends Biochem Sci 25:352-356

8. Adl SM, Simpson AGB, Lane CE et al (2012) The revised classification of eukaryotes. J Eukaryot Microbiol 59:429-514. https ://doi.org/10.1111/j.1550-7408.2012.00644.X

9. Takahashi Y, Tokumoto U (2002) A third bacterial system for the assembly of iron-sulfur clusters with homologs in archaea and plastids. J Biol Chem 277:28380-28383. https://doi.org/10.1074/ jbc.C200365200

10. Jacobson MR, Cash VL, Weiss MC et al (1989) Biochemical and genetic analysis of the nifUSVWZM cluster from Azotobacter vinelandii. Mol Gen Genet 219:49-57

11. Loiseau L, Ollagnier de Choudens S, Lascoux D et al (2005) Analysis of the heteromeric CsdA-CsdE cysteine desulfurase, assisting $\mathrm{Fe}-\mathrm{S}$ cluster biogenesis in Escherichia coli. J Biol Chem 280:26760-26769. https://doi.org/10.1074/jbc.M5040 67200

12. Stairs CW, Leger MM, Roger AJ (2015) Diversity and origins of anaerobic metabolism in mitochondria and related organelles. Philos Trans R Soc Lond B Biol Sci 370:20140326. https://doi. org/10.1098/rstb.2014.0326

13. Stairs CW, Eme L, Brown MW et al (2014) A SUF Fe-S cluster biogenesis system in the mitochondrion-related organelles of the anaerobic protist Pygsuia. Curr Biol 24:1176-1186. https://doi. org/10.1016/j.cub.2014.04.033

14. Lill R, Dutkiewicz R, Freibert SA et al (2015) The role of mitochondria and the CIA machinery in the maturation of cytosolic and nuclear iron-sulfur proteins. Eur J Cell Biol 94:280-291. https://doi.org/10.1016/j.ejcb.2015.05.002

15. Stehling O, Mascarenhas J, Vashisht AA et al (2013) Human CIA2A-FAM96A and CIA2B-FAM96B integrate iron homeostasis and maturation of different subsets of cytosolic-nuclear iron-sulfur proteins. Cell Metab 18:187-198. https://doi. org/10.1016/j.cmet.2013.06.015

16. Paul VD, Lill R (2015) Biogenesis of cytosolic and nuclear iron-sulfur proteins and their role in genome stability. BBAMol Cell Res 1853:1528-1539. https://doi.org/10.1016/j.bbamc r.2014.12.018

17. Balk J, Pilon M (2011) Ancient and essential: the assembly of iron-sulfur clusters in plants. Trends Plant Sci 16:218-226. https ://doi.org/10.1016/j.tplants.2010.12.006

18. Barras F, Loiseau L, Py B (2005) How Escherichia coli and Saccharomyces cerevisiae build $\mathrm{Fe} / \mathrm{S}$ proteins. Adv Microb Physiol 50:41-101. https://doi.org/10.1016/S0065-2911(05)50002-X

19. Roche B, Aussel L, Ezraty B et al (2013) Iron/sulfur proteins biogenesis in prokaryotes: formation, regulation and diversity. Biochim Biophys Acta 1827:455-469. https://doi.org/10.1016/j. bbabio.2012.12.010

20. Basu S, Netz DJ, Haindrich AC et al (2014) Cytosolic iron-sulphur protein assembly is functionally conserved and essential in procyclic and bloodstream Trypanosoma brucei. Mol Microbiol 93:897-910. https://doi.org/10.1111/mmi.12706

21. Iwasaki T (2010) Iron-sulfur world in aerobic and hyperthermoacidophilic archaea Sulfolobus. Archaea 2010:1-14. https:// doi.org/10.1155/2010/842639

22. Tsaousis AD, Ollagnier de Choudens S, Gentekaki E et al (2012) Evolution of $\mathrm{Fe} / \mathrm{S}$ cluster biogenesis in the anaerobic parasite Blastocystis. Proc Natl Acad Sci USA 109:10426-10431. https ://doi.org/10.1073/pnas.1116067109

23. Karnkowska A, Vacek V, Zubácová Z et al (2016) A eukaryote without a mitochondrial organelle. Curr Biol 26:1274-1284. https://doi.org/10.1016/j.cub.2016.03.053

24. Tachezy J, Sánchez LB, Müller M (2001) Mitochondrial type iron-sulfur cluster assembly in the amitochondriate eukaryotes Trichomonas vaginalis and Giardia intestinalis, as indicated 
by the phylogeny of IscS. Mol Biol Evol 18:1919-1928. https ://doi.org/10.1093/oxfordjournals.molbev.a003732

25. Freibert SA, Goldberg AV, Hacker C et al (2016) Evolutionary conservation and in vitro reconstitution of microsporidian iron-sulfur cluster biosynthesis. Nat Commun 8:1-12. https:// doi.org/10.1038/ncomms 13932

26. Dellibovi-Ragheb TA, Gisselberg JE, Prigge ST (2013) Parasites FeS up: iron-sulfur cluster biogenesis in eukaryotic pathogens. PLoS Pathog 9:e1003227. https://doi.org/10.1371/journ al.ppat. 1003227

27. Hjort K, Goldberg AV, Tsaousis AD et al (2010) Diversity and reductive evolution of mitochondria among microbial eukaryotes. Philos Trans R Soc Lond B Biol Sci 365:713-727. https ://doi.org/10.1073/pnas.90.7.2754

28. Leger MM, Kolísko M, Kamikawa R et al (2017) Organelles that illuminate the origins of Trichomonas hydrogenosomes and Giardia mitosomes. Nat Ecol Evol 1:0092. https://doi. org/10.1038/s41559-017-0092

29. Yan R, Konarev PV, Iannuzzi C et al (2013) Ferredoxin competes with bacterial frataxin in binding to the desulfurase IscS. J Biol Chem 288:24777-24787. https://doi.org/10.1074/jbc. M113.480327

30. Ayala-Castro C, Saini A, Outten FW (2008) Fe-S cluster assembly pathways in bacteria. Microbiol Mol Biol Rev 72:110-125. https://doi.org/10.1128/mmbr.00034-07 (table of contents)

31. Ollagnier-de-Choudens S, Mattioli T, Takahashi Y, Fontecave M (2001) Iron-sulfur cluster assembly: characterization of IscA and evidence for a specific and functional complex with ferredoxin. J Biol Chem 276:22604-22607. https://doi. org/10.1074/jbc.M102902200

32. Krebs C, Agar JN, Smith AD et al (2001) IscA, an alternate scaffold for Fe-S cluster biosynthesis. Biochemistry 40:1406914080. https://doi.org/10.1021/bi015656z

33. Vickery LE, Cupp-Vickery JR (2008) Molecular chaperones $\mathrm{HscA} / \mathrm{Ssq} 1$ and $\mathrm{HscB} / \mathrm{Jac} 1$ and their roles in iron-sulfur protein maturation. Crit Rev Biochem Mol Biol 42:95-111. https ://doi.org/10.1080/10409230701322298

34. Silberg JJ, Tapley TL, Hoff KG, Vickery LE (2004) Regulation of the HscA ATPase reaction cycle by the co-chaperone $\mathrm{HscB}$ and the iron-sulfur cluster assembly protein IscU. J Biol Chem 279:53924-53931. https://doi.org/10.1074/jbc.M410117200

35. Reyda MR, Fugate CJ, Jarrett JT (2009) A complex between biotin synthase and the iron-sulfur cluster assembly chaperone HscA that enhances in vivo cluster assembly. Biochemistry 48:10782-10792. https://doi.org/10.1021/bi901393t

36. Bonomi F, Iametti S, Morleo A et al (2008) Studies on the mechanism of catalysis of iron-sulfur cluster transfer from IscU $[2 \mathrm{Fe} 2 \mathrm{~S}]$ by $\mathrm{Hsc} \mathrm{A} / \mathrm{HscB}$ chaperones. Biochemistry 47:12795-12801. https://doi.org/10.1021/bi801565j

37. Chandramouli K, Johnson MK (2006) HscA and HscB stimulate $[2 \mathrm{Fe}-2 \mathrm{~S}]$ cluster transfer from Isc $\mathrm{U}$ to apoferredoxin in an ATP-dependent reaction. Biochemistry 45:11087-11095. https ://doi.org/10.1021/bi061237w

38. Hoff KG, Silberg JJ, Vickery LE (2000) Interaction of the iron-sulfur cluster assembly protein IscU with the Hsc66/ Hsc20 molecular chaperone system of Escherichia coli. Proc Natl Acad Sci USA 97:7790-7795. https://doi.org/10.1073/ pnas. 130201997

39. Bonomi F, Iametti S, Morleo A et al (2011) Facilitated transfer of IscU-[2Fe2S] clusters by chaperone-mediated ligand exchange. Biochemistry 50:9641-9650. https://doi.org/10.1021/bi201123z

40. Agar JN, Krebs C, Frazzon J et al (2000) IscU as a scaffold for iron-sulfur cluster biosynthesis: sequential assembly of [2Fe-2S] and $[4 \mathrm{Fe}-4 \mathrm{~S}]$ clusters in IscU. Biochemistry 39:7856-7862. https ://doi.org/10.1021/bi000931n
41. Chandramouli K, Unciuleac M-C, Naik S et al (2007) Formation and properties of [4Fe-4S] clusters on the IscU scaffold protein. Biochemistry 46:6804-6811. https://doi.org/10.1021/ bi6026659

42. Adinolfi S, Iannuzzi C, Prischi F et al (2009) Bacterial frataxin CyaY is the gatekeeper of iron-sulfur cluster formation catalyzed by IscS. Nat Struct Mol Biol 16:390-396. https://doi. org/10.1038/nsmb.1579

43. Loiseau L, Ollagnier de Choudens S, Nachin L et al (2003) Biogenesis of Fe-S cluster by the bacterial Suf system: SufS and SufE form a new type of cysteine desulfurase. J Biol Chem 278:38352-38359. https://doi.org/10.1074/jbc.M305953200

44. Outten FW, Djaman O, Storz G (2004) A suf operon requirement for $\mathrm{Fe}-\mathrm{S}$ cluster assembly during iron starvation in Escherichia coli. Mol Microbiol 52:861-872. https://doi.org/10.111 1/j.1365-2958.2004.04025.x

45. Outten FW, Wood MJ, Muñoz FM, Storz G (2003) The SufE protein and the SufBCD complex enhance SufS cysteine desulfurase activity as part of a sulfur transfer pathway for $\mathrm{Fe}-\mathrm{S}$ cluster assembly in Escherichia coli. J Biol Chem 278:45713-45719. https://doi.org/10.1074/jbc.M308004200

46. Mihara H, Esaki N (2002) Bacterial cysteine desulfurases: their function and mechanisms. Appl Microbiol Biotechnol 60:12-23. https://doi.org/10.1007/s00253-002-1107-4

47. Layer G, Gaddam SA, Ayala-Castro CN et al (2007) SufE transfers sulfur from SufS to SufB for iron-sulfur cluster assembly. J Biol Chem 282:13342-13350. https://doi.org/10.1074/jbc. M608555200

48. Wollers S, Layer G, Garcia Serres R et al (2010) Iron-sulfur (Fe-S) cluster assembly: the SufBCD complex is a new type of $\mathrm{Fe}-\mathrm{S}$ scaffold with a flavin redox cofactor. J Biol Chem 285:23331-23341. https://doi.org/10.1074/jbc.M110.127449

49. Chahal HK, Outten FW (2012) Separate FeS scaffold and carrier functions for $\operatorname{SufB}_{2} \mathrm{C}_{2}$ and SufA during in vitro maturation of [2Fe2S] Fdx. J Inorg Biochem 116:126-134. https://doi. org/10.1016/j.jinorgbio.2012.06.008

50. Saini A, Mapolelo DT, Chahal HK et al (2010) SufD and SufC ATPase activity are required for iron acquisition during in vivo Fe-S cluster formation on SufB. Biochemistry 49:9402-9412. https://doi.org/10.1021/bi1011546

51. Nachin L, Loiseau L, Expert D, Barras F (2003) SufC: an unorthodox cytoplasmic ABC/ATPase required for [Fe-S] biogenesis under oxidative stress. EMBO J 22:427-437. https://doi. org/10.1093/emboj/cdg061

52. Hirabayashi K, Yuda E, Tanaka N et al (2015) Functional dynamics revealed by the structure of the SufBCD complex, a novel ATP-binding cassette $(\mathrm{ABC})$ protein that serves as a scaffold for iron-sulfur cluster biogenesis. J Biol Chem 290:29717-29731. https://doi.org/10.1074/jbc.M115.680934

53. Vinella D, Brochier-Armanet C, Loiseau L et al (2009) Ironsulfur $(\mathrm{Fe} / \mathrm{S})$ protein biogenesis: phylogenomic and genetic studies of A-type carriers. PLoS Genet 5:e1000497. https://doi. org/10.1371/journal.pgen.1000497

54. Chahal HK, Dai Y, Saini A et al (2009) The SufBCD Fe-S scaffold complex interacts with SufA for Fe-S cluster transfer. Biochemistry 48:10644-10653. https://doi.org/10.1021/bi901518y

55. Outten FW (2015) Recent advances in the Suf Fe-S cluster biogenesis pathway: beyond the Proteobacteria. BBA Mol Cell Res 1853:1464-1469. https://doi.org/10.1016/j.bbamcr.2014.11.001

56. Yang J, Bitoun JP, Ding H (2006) Interplay of IscA and IscU in biogenesis of iron-sulfur clusters. J Biol Chem 281:2795627963. https://doi.org/10.1074/jbc.M601356200

57. Selbach BP, Chung AH, Scott AD et al (2013) Fe-S cluster biogenesis in Gram-positive bacteria: SufU is a zinc-dependent sulfur transfer protein. Biochemistry 53:152-160. https://doi. org/10.1021/bi4011978 
58. Albrecht AG, Netz DJA, Miethke M et al (2010) SufU is an essential iron-sulfur cluster scaffold protein in Bacillus subtilis. J Bacteriol 192:1643-1651. https://doi.org/10.1128/JB.01536-09

59. Riboldi GP, de Oliveira JS, Frazzon J (2011) Enterococcus faecalis SufU scaffold protein enhances SufS desulfurase activity by acquiring sulfur from its cysteine-153. BBA Proteins Proteom 1814:1910-1918. https://doi.org/10.1016/j.bbapap.2011.06.016

60. Mansy SS, Wu G, Surerus KK, Cowan JA (2002) Iron-sulfur cluster biosynthesis. Thermatoga maritima IscU is a structured iron-sulfur cluster assembly protein. J Biol Chem 277:2139721404. https://doi.org/10.1074/jbc.M201439200

61. Huet G, Daffe M, Saves I (2005) Identification of the Mycobacterium tuberculosis SUF machinery as the exclusive mycobacterial system of [Fe-S] cluster assembly: evidence for its implication in the pathogen's survival. J Bacteriol 187:6137-6146. https:// doi.org/10.1128/JB.187.17.6137-6146.2005

62. Olson JW, Agar JN, Johnson MK, Maier RJ (2000) Characterization of the NifU and NifS Fe-S cluster formation proteins essential for viability in Helicobacter pylori. Biochemistry 39:1621316219. https://doi.org/10.1021/bi001744s

63. Rincon-Enriquez G, Crété P, Barras F, Py B (2008) Biogenesis of $\mathrm{Fe} / \mathrm{S}$ proteins and pathogenicity: IscR plays a key role in allowing Erwinia chrysanthemi to adapt to hostile conditions. Mol Microbiol 67:1257-1273. https://doi.org/10.111 1/j.1365-2958.2008.06118.x

64. Glasner JD, Yang C-H, Reverchon S et al (2011) Genome sequence of the plant-pathogenic bacterium Dickeya dadantii 3937. J Bacteriol 193:2076-2077. https://doi.org/10.1128/ JB.01513-10

65. Arnold W, Rump A, Klipp W et al (1988) Nucleotide sequence of a 24,206-base-pair DNA fragment carrying the entire nitrogen fixation gene cluster of Klebsiella pneumoniae. J Mol Biol 203:715-738

66. Frazzon J, Dean DR (2003) Formation of iron-sulfur clusters in bacteria: an emerging field in bioinorganic chemistry. Curr Opin Chem Biol 7:166-173. https://doi.org/10.1016/S1367 -5931(03)00021-8

67. Curatti L, Ludden PW, Rubio LM (2006) NifB-dependent in vitro synthesis of the iron-molybdenum cofactor of nitrogenase. Proc Natl Acad Sci USA 103:5297-5301. https://doi.org/10.1073/ pnas.0601115103

68. Evans DJ, Jones R, Woodley PR et al (1991) Nucleotide sequence and genetic analysis of the Azotobacter chroococcum nifUSVWZM gene cluster, including a new gene (nifP) which encodes a serine acetyltransferase. J Bacteriol 173:5457-5469

69. Mihara H, Kurihara T, Yoshimura T et al (1997) Cysteine sulfinate desulfinase, a NIFS-like protein of Escherichia coli with selenocysteine lyase and cysteine desulfurase activities. Gene cloning, purification, and characterization of a novel pyridoxal enzyme. J Biol Chem 272:22417-22424

70. Mihara H, Maeda M, Fujii T et al (1999) A nifS-like gene, csdB, encodes an Escherichia coli counterpart of mammalian selenocysteine lyase. Gene cloning, purification, characterization and preliminary X-ray crystallographic studies. J Biol Chem 274:14768-14772

71. Mihara H, Kurihara T, Yoshimura T, Esaki N (2000) Kinetic and mutational studies of three NifS homologs from Escherichia coli: mechanistic difference between L-cysteine desulfurase and L-selenocysteine lyase reactions. J Biochem 127:559-567

72. Fontecave M, Ollagnier de Choudens S (2008) Iron-sulfur cluster biosynthesis in bacteria: mechanisms of cluster assembly and transfer. Arch Biochem Biophys 474:226-237. https://doi. org/10.1016/j.abb.2007.12.014

73. Trotter V, Vinella D, Loiseau L et al (2009) The CsdA cysteine desulphurase promotes $\mathrm{Fe} / \mathrm{S}$ biogenesis by recruiting Suf components and participates to a new sulphur transfer pathway by recruiting CsdL (ex-YgdL), a ubiquitin-modifyinglike protein. Mol Microbiol 74:1527-1542. https://doi.org/10.1 111/j.1365-2958.2009.06954.x

74. Ali V, Nozaki T (2013) Iron-sulphur clusters, their biosynthesis, and biological functions in protozoan parasites. Adv Parasitol 83:1-92. https://doi.org/10.1016/B978-0-12-407705-8.00001-X

75. Kumar B, Chaubey S, Shah P et al (2011) Interaction between sulphur mobilisation proteins SufB and SufC: evidence for an iron-sulphur cluster biogenesis pathway in the apicoplast of Plasmodium falciparum. Int J Parasitol 41:991-999. https://doi. org/10.1016/j.ijpara.2011.05.006

76. Nývltová E, Sutak R, Harant K et al (2013) NIF-type iron-sulfur cluster assembly system is duplicated and distributed in the mitochondria and cytosol of Mastigamoeba balamuthi. Proc Natl Acad Sci USA 110:7371-7376. https://doi.org/10.1073/ pnas. 1219590110

77. Ali V, Shigeta Y, Tokumoto U et al (2004) An intestinal parasitic protist, Entamoeba histolytica, possesses a non-redundant nitrogen fixation-like system for iron-sulfur cluster assembly under anaerobic conditions. J Biol Chem 279:16863-16874. https://doi. org/10.1074/jbc.M313314200

78. Poliak P, Van Hoewyk D, Oborník M et al (2009) Functions and cellular localization of cysteine desulfurase and selenocysteine lyase in Trypanosoma brucei. FEBS J 277:383-393. https:// doi.org/10.1111/j.1742-4658.2009.07489.x

79. Richards TA, van der Giezen M (2006) Evolution of the Isd11IscS complex reveals a single alpha-proteobacterial endosymbiosis for all eukaryotes. Mol Biol Evol 23:1341-1344. https://doi. org/10.1093/molbev/ms1001

80. Wiedemann N, Urzica E, Guiard B et al (2006) Essential role of Isd11 in mitochondrial iron-sulfur cluster synthesis on Isu scaffold proteins. EMBO J 25:184-195. https://doi.org/10.1038/ sj.emboj.7600906

81. Shi Y, Ghosh MC, Tong W-H, Rouault TA (2009) Human ISD11 is essential for both iron-sulfur cluster assembly and maintenance of normal cellular iron homeostasis. Hum Mol Gen 18:3014-3025. https://doi.org/10.1093/hmg/ddp239

82. Friemel M, Marelja Z, Li K, Leimkühler S (2017) The N-terminus of iron-sulfur cluster assembly factor ISD11 is crucial for subcellular targeting and interaction with L-cysteine desulfurase NFS1. Biochemistry 56:1797-1808. https://doi.org/10.1021/acs. biochem.6b01239

83. Biederbick A, Stehling O, Rösser R et al (2006) Role of human mitochondrial Nfs1 in cytosolic iron-sulfur protein biogenesis and iron regulation. Mol Cell Biol 26:5675-5687. https://doi. org/10.1128/MCB.00112-06

84. Van Vranken JG, Jeong M-Y, Wei P et al (2016) The mitochondrial acyl carrier protein (ACP) coordinates mitochondrial fatty acid synthesis with iron sulfur cluster biogenesis. Elife. https:// doi.org/10.7554/eLife.17828

85. Cory SA, Van Vranken JG, Brignole EJ et al (2017) Structure of human $\mathrm{Fe}-\mathrm{S}$ assembly subcomplex reveals unexpected cysteine desulfurase architecture and acyl-ACP-ISD11 interactions. Proc Natl Acad Sci USA 114:E5325-E5334. https://doi.org/10.1073/ pnas. 1702849114

86. Boniecki MT, Freibert SA, Mühlenhoff U et al (2017) Structure and functional dynamics of the mitochondrial $\mathrm{Fe} / \mathrm{S}$ cluster synthesis complex. Nat Commun 8:1287. https://doi.org/10.1038/ s41467-017-01497-1

87. Sheftel AD, Stehling O, Pierik AJ et al (2010) Humans possess two mitochondrial ferredoxins, Fdx 1 and Fdx2, with distinct roles in steroidogenesis, heme, and $\mathrm{Fe} / \mathrm{S}$ cluster biosynthesis. Proc Natl Acad Sci USA 107:11775-11780. https://doi. org/10.1073/pnas.1004250107

88. Shan Y, Cortopassi G (2012) HSC20 interacts with frataxin and is involved in iron-sulfur cluster biogenesis and iron homeostasis. 
Hum Mol Gen 21:1457-1469. https://doi.org/10.1093/hmg/ddr58 2

89. Beilschmidt LK, Ollagnier de Choudens S, Fournier M et al (2017) ISCA1 is essential for mitochondrial $\mathrm{Fe}_{4} \mathrm{~S}_{4}$ biogenesis in vivo. Nat Commun 8:15124. https://doi.org/10.1038/ncomm s15124

90. Ciofi-Baffoni S, Nasta V, Banci L (2018) Protein networks in the maturation of human iron-sulfur proteins. Metallomics 10:4972. https://doi.org/10.1039/c7mt00269f

91. Tong W-H, Rouault T (2000) Distinct iron-sulfur cluster assembly complexes exist in the cytosol and mitochondria of human cells. EMBO J 19:5692-5700. https://doi.org/10.1093/emboj $/ 19.21 .5692$

92. Uhrigshardt H, Singh A, Kovtunovych G et al (2010) Characterization of the human HSC20, an unusual DnaJ type III protein, involved in iron-sulfur cluster biogenesis. Hum Mol Gen 19:3816-3834. https://doi.org/10.1093/hmg/ddq301

93. Uhrigshardt H, Rouault TA, Missirlis F (2013) Insertion mutants in Drosophila melanogaster Hsc20 halt larval growth and lead to reduced iron-sulfur cluster enzyme activities and impaired iron homeostasis. J Biol Inorg Chem 18:441-449. https://doi. org/10.1007/s00775-013-0988-2

94. Schilke B, Williams B, Knieszner H et al (2006) Evolution of mitochondrial chaperones utilized in $\mathrm{Fe}-\mathrm{S}$ cluster biogenesis. Curr Biol 16:1660-1665. https://doi.org/10.1016/j. cub.2006.06.069

95. Maio N, Singh A, Uhrigshardt H et al (2014) Cochaperone binding to LYR motifs confers specificity of iron sulfur cluster delivery. Cell Metab 19:445-457. https://doi.org/10.1016/j. cmet.2014.01.015

96. Bridwell-Rabb J, Iannuzzi C, Pastore A, Barondeau DP (2012) Effector role reversal during evolution: the case of Frataxin in $\mathrm{Fe}-\mathrm{S}$ cluster biosynthesis. Biochemistry 51:2506-2514. https:// doi.org/10.1021/bi201628j

97. Bridwell-Rabb J, Fox NG, Tsai C-L et al (2014) Human Frataxin activates $\mathrm{Fe}-\mathrm{S}$ cluster biosynthesis by facilitating sulfur transfer chemistry. Biochemistry 53:4904-4913. https://doi.org/10.1021/ bi500532e

98. Schmucker S, Martelli A, Colin F et al (2011) Mammalian frataxin: an essential function for cellular viability through an interaction with a preformed ISCU/NFS1/ISD11 iron-sulfur assembly complex. PLoS One 6:e16199. https://doi.org/10.1371/ journal.pone.0016199

99. Cai K, Frederick RO, Kim JH et al (2013) Human mitochondrial chaperone (mtHSP70) and cysteine desulfurase (NFS1) bind preferentially to the disordered conformation, whereas co-chaperone (HSC20) binds to the structured conformation of the iron-sulfur cluster scaffold protein (ISCU). J Biol Chem 288:28755-28770. https://doi.org/10.1074/jbc.M113.482042

100. Banci L, Brancaccio D, Ciofi-Baffoni S et al (2014) [2Fe-2S] cluster transfer in iron-sulfur protein biogenesis. Proc Natl Acad Sci USA 111:6203-6208. https://doi.org/10.1073/pnas.14001 02111

101. Camaschella C, Campanella A, De Falco L et al (2007) The human counterpart of zebrafish shiraz shows sideroblastic-like microcytic anemia and iron overload. Blood 110:1353-1358. https://doi.org/10.1182/blood-2007-02-072520

102. Uzarska MA, Dutkiewicz R, Freibert S-A et al (2013) The mitochondrial Hsp70 chaperone Ssq1 facilitates Fe/S cluster transfer from Isu 1 to Grx 5 by complex formation. Mol Biol Cell 24:1830-1841. https://doi.org/10.1091/mbc.E12-09-0644

103. Dutkiewicz R, Schilke B, Knieszner H et al (2003) Ssq1, a mitochondrial Hsp70 involved in iron-sulfur $(\mathrm{Fe} / \mathrm{S})$ center biogenesis. Similarities to and differences from its bacterial counterpart. J Biol Chem 278:29719-29727. https://doi.org/10.1074/jbc. M303527200
104. Rodríguez-Manzaneque MT, Tamarit J, Bellí G et al (2002) Grx 5 is a mitochondrial glutaredoxin required for the activity of iron/sulfur enzymes. Mol Biol Cell 13:1109-1121. https:// doi.org/10.1091/mbc.01-10-0517

105. Kim K-D, Chung W-H, Kim H-J et al (2010) Monothiol glutaredoxin Grx 5 interacts with $\mathrm{Fe}-\mathrm{S}$ scaffold proteins Isa1 and Isa2 and supports $\mathrm{Fe}-\mathrm{S}$ assembly and DNA integrity in mitochondria of fission yeast. Biochem Biophys Res Commun 392:467-472. https://doi.org/10.1016/j.bbrc.2010.01.051

106. Vilella F, Alves R, Rodríguez-Manzaneque MT et al (2004) Evolution and cellular function of monothiol glutaredoxins: involvement in iron-sulphur cluster assembly. Comp Funct Genomics 5:328-341. https://doi.org/10.1002/cfg.406

107. Sheftel AD, Wilbrecht C, Stehling O et al (2012) The human mitochondrial ISCA1, ISCA2, and IBA57 proteins are required for [4Fe-4S] protein maturation. Mol Biol Cell 23:1157-1166. https://doi.org/10.1091/mbc.E11-09-0772

108. Alaimo JT, Besse A, Alston CL et al (2018) Loss-of-function mutations in ISCA2 disrupt $4 \mathrm{Fe}-4 \mathrm{~S}$ cluster machinery and cause a fatal leukodystrophy with hyperglycinemia and mtDNA depletion. Hum Mutat 39:537-549. https://doi.org/10.1002/ humu.23396

109. Brancaccio D, Gallo A, Mikolajczyk M et al (2014) Formation of $[4 \mathrm{Fe}-4 \mathrm{~S}]$ clusters in the mitochondrial iron-sulfur cluster assembly machinery. J Am Chem Soc 136:16240-16250. https ://doi.org/10.1021/ja507822j

110. Mühlenhoff U, Gerl MJ, Flauger B et al (2007) The ISC proteins Isa 1 and Isa2 are required for the function but not for the de novo synthesis of the $\mathrm{Fe} / \mathrm{S}$ clusters of biotin synthase in Saccharomyces cerevisiae. Eukaryot Cell 6:495-504. https:// doi.org/10.1128/EC.00191-06

111. Mühlenhoff U, Richter N, Pines O et al (2011) Specialized function of yeast Isa1 and Isa2 proteins in the maturation of mitochondrial [4Fe-4S] proteins. J Biol Chem 286:4120541216. https://doi.org/10.1074/jbc.M111.296152

112. Kaut A, Lange H, Diekert $K$ et al (2000) Isa1p is a component of the mitochondrial machinery for maturation of cellular iron-sulfur proteins and requires conserved cysteine residues for function. J Biol Chem 275:15955-15961. https://doi. org/10.1074/jbc.M909502199

113. Gelling C, Dawes IW, Richhardt N et al (2008) Mitochondrial Iba57p is required for Fe/S cluster formation on aconitase and activation of radical SAM enzymes. Mol Cell Biol 28:18511861. https://doi.org/10.1128/MCB.01963-07

114. Sánchez LA, Gomez-Gallardo M, Díaz-Pérez AL et al (2018) Iba57p participates in maturation of a $[2 \mathrm{Fe}-2 \mathrm{~S}]$-cluster Rieske protein and in formation of supercomplexes III/IV of Saccharomyces cerevisiae electron transport chain. Mitochondrion. https://doi.org/10.1016/j.mito.2018.01.003

115. Braymer JJ, Lill R (2017) Iron-sulfur cluster biogenesis and trafficking in mitochondria. J Biol Chem 292:12754-12763. https://doi.org/10.1074/jbc.R117.787101

116. Sheftel AD, Stehling O, Pierik AJ et al (2009) Human Ind1, an iron-sulfur cluster assembly factor for respiratory complex I. Mol Cell Biol 29:6059-6073. https://doi.org/10.1128/ MCB.00817-09

117. Bych K, Kerscher S, Netz DJA et al (2008) The iron-sulphur protein Ind1 is required for effective complex I assembly. EMBO J 27:1736-1746. https://doi.org/10.1038/emboj.2008.98

118. Tong W-H, Jameson GNL, Huynh BH, Rouault TA (2003) Subcellular compartmentalization of human $\mathrm{Nfu}$, an iron-sulfur cluster scaffold protein, and its ability to assemble a [4Fe-4S] cluster. Proc Natl Acad Sci USA 100:9762-9767. https://doi. org/10.1073/pnas.1732541100

119. Léon S, Touraine B, Ribot C et al (2003) Iron-sulphur cluster assembly in plants: distinct NFU proteins in mitochondria and 
plastids from Arabidopsis thaliana. Biochem J 371:823-830. https://doi.org/10.1042/BJ20021946

120. Melber A, Na U, Vashisht A et al (2016) Role of Nfu1 and Bol3 in iron-sulfur cluster transfer to mitochondrial clients. Elife 5:186. https://doi.org/10.7554/eLife.15991

121. Gao H, Subramanian S, Couturier J et al (2013) Arabidopsis thaliana $\mathrm{Nfu} 2$ accommodates $[2 \mathrm{Fe}-2 \mathrm{~S}]$ or $[4 \mathrm{Fe}-4 \mathrm{~S}]$ clusters and is competent for in vitro maturation of chloroplast $[2 \mathrm{Fe}-2 \mathrm{~S}]$ and [4Fe-4S] cluster-containing proteins. Biochemistry 52:66336645. https://doi.org/10.1021/bi4007622

122. Wachnowsky C, Fidai I, Cowan JA (2016) Iron-sulfur cluster exchange reactions mediated by the human Nfu protein. J Biol Inorg Chem 21:825-836. https://doi.org/10.1007/s0077 5-016-1381-8

123. Benoit SL, Holland AA, Johnson MK, Maier RJ (2018) Iron-sulfur protein maturation in Helicobacter pylori: identifying a Nfutype cluster carrier protein and its iron-sulfur protein targets. Mol Microbiol. https://doi.org/10.1111/mmi.13942

124. Tonduti D, Dorboz I, Imbard A et al (2015) New spastic paraplegia phenotype associated to mutation of NFU1. Orphanet J Rare Dis 10:13. https://doi.org/10.1186/s13023-015-0237-6

125. Navarro-Sastre A, Tort F, Stehling O et al (2011) A fatal mitochondrial disease is associated with defective NFU1 function in the maturation of a subset of mitochondrial $\mathrm{Fe}-\mathrm{S}$ proteins. Am J Hum Genet 89:656-667. https://doi.org/10.1016/j. ajhg.2011.10.005

126. Cameron JM, Janer A, Levandovskiy V et al (2011) Mutations in iron-sulfur cluster scaffold genes NFU1 and BOLA3 cause a fatal deficiency of multiple respiratory chain and 2-oxoacid dehydrogenase enzymes. Am J Hum Genet 89:486-495. https:// doi.org/10.1016/j.ajhg.2011.08.011

127. Uzarska MA, Nasta V, Weiler BD et al (2016) Mitochondrial Bol1 and Bol3 function as assembly factors for specific iron-sulfur proteins. Elife 5:e16673. https://doi.org/10.7554/eLife.16673

128. Willems P, Wanschers BFJ, Esseling J et al (2013) BOLA1 Is an aerobic protein that prevents mitochondrial morphology changes induced by glutathione depletion. Antioxid Redox Signal 18:129-138. https://doi.org/10.1089/ars.2011.4253

129. Frey AG, Palenchar DJ, Wildemann JD, Philpott CC (2016) A glutaredoxin BolA complex serves as an iron-sulfur cluster chaperone for the cytosolic cluster assembly machinery. J Biol Chem 291:22344-22356. https://doi.org/10.1074/jbc.M116.744946

130. Sipos K, Lange H, Fekete $Z$ et al (2002) Maturation of cytosolic iron-sulfur proteins requires glutathione. J Biol Chem 277:26944-26949. https://doi.org/10.1074/jbc.M200677200

131. Kispal G, Csere P, Prohl C, Lill R (1999) The mitochondrial proteins Atm1p and Nfs1p are essential for biogenesis of cytosolic Fe/S proteins. EMBO J 18:3981-3989. https://doi.org/10.1093/ emboj/18.14.3981

132. Leighton J, Schatz G (1995) An ABC transporter in the mitochondrial inner membrane is required for normal growth of yeast. EMBO J 14:188-195

133. Balk J, Pierik AJ, Netz DJA et al (2004) The hydrogenaselike Nar1p is essential for maturation of cytosolic and nuclear iron-sulphur proteins. EMBO J 23:2105-2115. https://doi. org/10.1038/sj.emboj.7600216

134. Stehling O, Lill R (2013) The role of mitochondria in cellular iron-sulfur protein biogenesis: mechanisms, connected processes, and diseases. Cold Spring Harb Perspect Biol 5:a011312. https://doi.org/10.1101/cshperspect.a011312

135. Srinivasan V, Pierik AJ, Lill R (2014) Crystal structures of nucleotide-free and glutathione-bound mitochondrial $\mathrm{ABC}$ transporter Atm1. Science 343:1137-1140. https://doi.org/10.1126/scien ce. 1246729
136. Roy A, Solodovnikova N, Nicholson T et al (2003) A novel eukaryotic factor for cytosolic $\mathrm{Fe}-\mathrm{S}$ cluster assembly. EMBO J 22:4826-4835. https://doi.org/10.1093/emboj/cdg455

137. Hausmann A, Aguilar Netz DJ, Balk J et al (2005) The eukaryotic P loop NTPase Nbp35: an essential component of the cytosolic and nuclear iron-sulfur protein assembly machinery. Proc Natl Acad Sci USA 102:3266-3271. https://doi.org/10.1073/ pnas.0406447102

138. Netz DJA, Pierik AJ, Stümpfig M et al (2007) The Cfd1-Nbp35 complex acts as a scaffold for iron-sulfur protein assembly in the yeast cytosol. Nat Chem Biol 3:278-286. https://doi.org/10.1038/ nchembio872

139. Boyd JM, Drevland RM, Downs DM, Graham DE (2009) Archaeal ApbC/Nbp35 homologs function as iron-sulfur cluster carrier proteins. J Bacteriol 191:1490-1497. https://doi. org/10.1128/JB.01469-08

140. Netz DJA, Pierik AJ, Stumpfig M et al (2012) A bridging $[4 \mathrm{Fe}-4 \mathrm{~S}]$ cluster and nucleotide binding are essential for function of the Cfd1-Nbp35 complex as a scaffold in iron-sulfur protein maturation. J Biol Chem 287:12365-12378. https://doi. org/10.1074/jbc.M111.328914

141. Stehling O, Netz DJA, Niggemeyer B et al (2008) Human Nbp35 is essential for both cytosolic iron-sulfur protein assembly and iron homeostasis. Mol Cell Biol 28:5517-5528. https://doi. org/10.1128/MCB.00545-08

142. Bych K, Netz DJA, Vigani G et al (2008) The essential cytosolic iron-sulfur protein $\mathrm{Nbp} 35$ acts without $\mathrm{Cfd} 1$ partner in the green lineage. J Biol Chem 283:35797-35804. https://doi.org/10.1074/ jbc.M807303200

143. Pyrih J, Pyrihová E, Kolísko M et al (2016) Minimal cytosolic iron-sulfur cluster assembly machinery of Giardia intestinalis is partially associated with mitosomes. Mol Microbiol 102:701714. https://doi.org/10.1111/mmi.13487

144. Netz DJA, Stümpfig M, Doré C et al (2010) Tah18 transfers electrons to Dre2 in cytosolic iron-sulfur protein biogenesis. Nat Chem Biol 6:758-765. https://doi.org/10.1038/nchembio.432

145. Zhang Y, Lyver ER, Nakamaru-Ogiso E et al (2008) Dre2, a conserved eukaryotic $\mathrm{Fe} / \mathrm{S}$ cluster protein, functions in cytosolic $\mathrm{Fe} / \mathrm{S}$ protein biogenesis. Mol Cell Biol 28:5569-5582. https:// doi.org/10.1128/MCB.00642-08

146. Peleh V, Riemer J, Dancis A, Herrmann JM (2014) Protein oxidation in the intermembrane space of mitochondria is substratespecific rather than general. Microb Cell 1:81-93. https://doi. org/10.15698/mic2014.01.130

147. Banci L, Bertini I, Ciofi-Baffoni S et al (2011) Anamorsin is a $[2 \mathrm{Fe}-2 \mathrm{~S}]$ cluster-containing substrate of the Mia40-dependent mitochondrial protein trapping machinery. Chem Biol 18:794804. https://doi.org/10.1016/j.chembiol.2011.03.015

148. Netz DJA, Genau HM, Weiler BD et al (2016) The conserved protein Dre2 uses essential [2Fe-2S] and [4Fe-4S] clusters for its function in cytosolic iron-sulfur protein assembly. Biochem J 473:2073-2085. https://doi.org/10.1042/BCJ20160416

149. Banci L, Ciofi-Baffoni S, Gajda K et al (2015) N-terminal domains mediate $[2 \mathrm{Fe}-2 \mathrm{~S}]$ cluster transfer from glutaredoxin-3 to anamorsin. Nat Chem Biol 11:772-778. https://doi.org/10.1038/ nchembio. 1892

150. Balk J, Aguilar Netz DJ, Tepper K et al (2005) The essential WD40 protein Cia1 is involved in a late step of cytosolic and nuclear iron-sulfur protein assembly. Mol Cell Biol 25:1083310841. https://doi.org/10.1128/MCB.25.24.10833-10841.2005

151. Stehling O, Vashisht AA, Mascarenhas J et al (2012) MMS19 assembles iron-sulfur proteins required for DNA metabolism and genomic integrity. Science 337:195-199. https://doi.org/10.1126/ science. 1219723

152. Gari K, Ortiz AML, Borel V et al (2012) MMS19 links cytoplasmic iron-sulfur cluster assembly to DNA metabolism. 
Science 337:243-245. https://doi.org/10.1126/science.12196 64

153. Odermatt DC, Gari K (2017) The CIA targeting complex is highly regulated and provides two distinct binding sites for client iron-sulfur proteins. Cell Rep 18:1434-1443. https://doi. org/10.1016/j.celrep.2017.01.037

154. Srinivasan V, Netz DJA, Webert $H$ et al (2007) Structure of the yeast WD40 domain protein Cia1, a component acting late in iron-sulfur protein biogenesis. Structure 15:1246-1257. https:// doi.org/10.1016/j.str.2007.08.009

155. Prakash L, Prakash S (1979) Three additional genes involved in pyrimidine dimer removal in Saccharomyces cerevisiae: RAD7, RAD14 and MMS19. Mol Gen Genet 176:351-359. https://doi. org/10.1007/BF00333097

156. Li F, Martienssen R, Cande WZ (2011) Coordination of DNA replication and histone modification by the Rik1-Dos 2 complex. Nature 475:244-248. https://doi.org/10.1038/nature10161

157. Eisenstein RS (2000) Iron regulatory proteins and the molecular control of mammalian iron metabolism. Annu Rev Nutr 20:627662. https://doi.org/10.1146/annurev.nutr.20.1.627

158. Mühlenhoff U, Molik S, Godoy JR et al (2010) Cytosolic monothiol glutaredoxins function in intracellular iron sensing and trafficking via their bound iron-sulfur cluster. Cell Metab 12:373-385. https://doi.org/10.1016/j.cmet.2010.08.001

159. Yarunin A, Panse VG, Petfalski E et al (2005) Functional link between ribosome formation and biogenesis of iron-sulfur proteins. EMBO J 24:580-588. https://doi.org/10.1038/sj.emboj .7600540

160. Van Ho A, Ward DM, Kaplan J (2002) Transition metal transport in yeast. Annu Rev Microbiol 56:237-261. https://doi. org/10.1146/annurev.micro.56.012302.160847

161. Ojeda L, Keller G, Mühlenhoff U et al (2006) Role of glutaredoxin- 3 and glutaredoxin- 4 in the iron regulation of the Aft 1 transcriptional activator in Saccharomyces cerevisiae. J Biol Chem 281:17661-17669. https://doi.org/10.1074/jbc.M6021 65200

162. Pujol-Carrion N, Bellí G, Herrero E et al (2006) Glutaredoxins Grx3 and Grx4 regulate nuclear localisation of Aft1 and the oxidative stress response in Saccharomyces cerevisiae. J Cell Sci 119:4554-4564. https://doi.org/10.1242/jcs.03229

163. Chen OS, Crisp RJ, Valachovic M et al (2004) Transcription of the yeast iron regulon does not respond directly to iron but rather to iron-sulfur cluster biosynthesis. J Biol Chem 279:2951329518. https://doi.org/10.1074/jbc.M403209200

164. Rutherford JC, Ojeda L, Balk J et al (2005) Activation of the iron regulon by the yeast Aft1/Aft2 transcription factors depends on mitochondrial but not cytosolic iron-sulfur protein biogenesis. J Biol Chem 280:10135-10140. https://doi.org/10.1074/jbc. M413731200

165. Kumánovics A, Chen OS, Li L et al (2008) Identification of FRA1 and FRA2 as genes involved in regulating the yeast iron regulon in response to decreased mitochondrial iron-sulfur cluster synthesis. J Biol Chem 283:10276-10286. https://doi. org/10.1074/jbc.M801160200

166. Li Y (1995) Yeast global transcriptional regulators Sin 4 and Rgr1 are components of mediator complex/RNA polymerase II holoenzyme. Proc Natl Acad Sci USA 92:10864-10868. https://doi. org/10.1073/pnas.1714341115

167. Aldea M, Hernández-Chico C, la Campa de AG et al (1988) Identification, cloning, and expression of bolA, an ftsZ-dependent morphogene of Escherichia coli. J Bacteriol 170:5169-5176. https://doi.org/10.1128/jb.170.11.5169-5176.1988

168. Li H, Mapolelo DT, Dingra NN et al (2011) Histidine 103 in Fra2 is an iron-sulfur cluster ligand in the $[2 \mathrm{Fe}-2 \mathrm{~S}] \mathrm{Fra} 2-\mathrm{Grx} 3$ complex and is required for in vivo iron signaling in yeast. J Biol Chem 286:867-876. https://doi.org/10.1074/jbc.M110.184176
169. Haunhorst P, Berndt C, Eitner S et al (2010) Characterization of the human monothiol glutaredoxin 3 (PICOT) as iron-sulfur protein. Biochem Biophys Res Commun 394:372-376. https:// doi.org/10.1016/j.bbrc.2010.03.016

170. Hampl V, Hug L, Leigh JW et al (2009) Phylogenomic analyses support the monophyly of Excavata and resolve relationships among eukaryotic "supergroups". Proc Natl Acad Sci USA 106:3859-3864. https://doi.org/10.1073/pnas.0807880106

171. Derelle R, Torruella G, Klimeš V et al (2015) Bacterial proteins pinpoint a single eukaryotic root. Proc Natl Acad Sci USA 112:E693-E699. https://doi.org/10.1073/pnas.1420657112

172. Lukeš J, Basu S (2015) Fe/S protein biogenesis in trypanosomes-a review. Biochim Biophys Acta 1853:1481-1492. https ://doi.org/10.1016/j.bbamcr.2014.08.015

173. Hannaert V, Bringaud F, Opperdoes FR, Michels PA (2003) Evolution of energy metabolism and its compartmentation in Kinetoplastida. Kinetoplastid Biol Dis 2:11. https://doi. org/10.1186/1475-9292-2-11

174. Basu S, Horáková E, Lukeš J (2016) Iron-associated biology of Trypanosoma brucei. BBA Gen Subjects 1860:363-370. https:// doi.org/10.1016/j.bbagen.2015.10.027

175. Smíd O, Horáková E, Vilímová V et al (2006) Knock-downs of iron-sulfur cluster assembly proteins IscS and IscU downregulate the active mitochondrion of procyclic Trypanosoma brucei. J Biol Chem 281:28679-28686. https://doi.org/10.1074/ jbc.M513781200

176. Paris Z, Changmai P, Rubio MAT et al (2010) The Fe/S cluster assembly protein Isd 11 is essential for tRNA thiolation in Trypanosoma brucei. J Biol Chem 285:22394-22402. https:// doi.org/10.1074/jbc.M109.083774

177. Changmai P, Horáková E, Long S et al (2013) Both human ferredoxins equally efficiently rescue ferredoxin deficiency in Trypanosoma brucei. Mol Microbiol 89:135-151. https://doi. org/10.1111/mmi.12264

178. Comini MA, Rettig J, Dirdjaja N et al (2008) Monothiol glutaredoxin-1 is an essential iron-sulfur protein in the mitochondrion of african trypanosomes. J Biol Chem 283:27785-27798. https ://doi.org/10.1074/jbc.M802010200

179. Long S, Jirků M, Ayala FJ, Lukeš J (2008) Mitochondrial localization of human frataxin is necessary but processing is not for rescuing frataxin deficiency in Trypanosoma brucei. Proc Natl Acad Sci USA 105:13468-13473. https://doi.org/10.1073/ pnas.0806762105

180. Long S, Changmai P, Tsaousis AD et al (2011) Stage-specific requirement for Isa1 and Isa2 proteins in the mitochondrion of Trypanosoma brucei and heterologous rescue by human and Blastocystis orthologues. Mol Microbiol 81:1403-1418. https:// doi.org/10.1111/j.1365-2958.2011.07769.x

181. Horáková E, Changmai P, Paris Z et al (2015) Simultaneous depletion of Atm and Mdl rebalances cytosolic $\mathrm{Fe}-\mathrm{S}$ cluster assembly but not heme import into the mitochondrion of Trypanosoma brucei. FEBS J 282:4157-4175. https://doi.org/10.1111/ febs.13411

182. Basu S, Leonard JC, Desai N et al (2013) Divergence of Erv1associated mitochondrial import and export pathways in trypanosomes and anaerobic protists. Eukaryot Cell 12:343-355. https ://doi.org/10.1128/EC.00304-12

183. Haindrich AC, Boudová M, Vancová M et al (2017) The intermembrane space protein Erv1 of Trypanosoma brucei is essential for mitochondrial $\mathrm{Fe}-\mathrm{S}$ cluster assembly and operates alone. Mol Biochem Parasitol 214:47-51. https://doi.org/10.1016/j.molbi opara.2017.03.009

184. Kovářová J, Horáková E, Changmai P et al (2014) Mitochondrial and nucleolar localization of cysteine desulfurase Nfs and the scaffold protein Isu in Trypanosoma brucei. Eukaryot Cell 13:353-362. https://doi.org/10.1128/EC.00235-13 
185. Benz C, Kovářová J, Králová-Hromadová I et al (2016) Roles of the Nfu Fe-S targeting factors in the trypanosome mitochondrion. Int J Parasitol 46:641-651. https://doi.org/10.1016/j.ijpar a.2016.04.006

186. Saunders EC, $\mathrm{Ng} \mathrm{WW}$, Kloehn J et al (2014) Induction of a stringent metabolic response in intracellular stages of Leishmania mexicana leads to increased dependence on mitochondrial metabolism. PLoS Pathog 10:e1003888. https://doi.org/10.1371/ journal.ppat.1003888

187. Pratap Singh K, Zaidi A, Anwar S et al (2014) Reactive oxygen species regulates expression of iron-sulfur cluster assembly protein IscS of Leishmania donovani. Free Radic Biol Med 75:195209. https://doi.org/10.1016/j.freeradbiomed.2014.07.017

188. Filser M, Comini MA, Molina-Navarro MM et al (2008) Cloning, functional analysis, and mitochondrial localization of Trypanosoma brucei monothiol glutaredoxin-1. Biol Chem 389:21-32. https://doi.org/10.1515/BC.2007.147

189. Comini MA, Krauth-Siegel RL, Bellanda M (2013) Mono- and dithiol glutaredoxins in the trypanothione-based redox metabolism of pathogenic trypanosomes. Antioxid Redox Signal 19:708-722. https://doi.org/10.1089/ars.2012.4932

190. Manta B, Pavan C, Sturlese M et al (2013) Iron-sulfur cluster binding by mitochondrial monothiol glutaredoxin-1 of Trypanosoma brucei: molecular basis of iron-sulfur cluster coordination and relevance for parasite infectivity. Antioxid Redox Signal 19:665-682. https://doi.org/10.1089/ars.2012.4859

191. Pánek T, Čepička I (2012) Diversity of heterolobosea. Genet Divers Microorg. https://doi.org/10.5772/35333

192. De Jonckheere JF, Baumgartner M, Opperdoes FR, Stetter KO (2009) Marinamoeba thermophila, a new marine heterolobosean amoeba growing at $50{ }^{\circ} \mathrm{C}$. Eur J Protistol 45:231-236. https:// doi.org/10.1016/j.ejop.2009.01.001

193. Park JS, Simpson AGB, Lee WJ, Cho BC (2007) Ultrastructure and phylogenetic placement within Heterolobosea of the previously unclassified, extremely halophilic heterotrophic flagellate Pleurostomum flabellatum (Ruinen 1938). Ann Anat 158:397413. https://doi.org/10.1016/j.protis.2007.03.004

194. De Jonckheere JF (2006) Isolation and molecular identification of free-living amoebae of the genus Naegleria from Arctic and sub-Antarctic regions. Eur J Protistol 42:115-123. https://doi. org/10.1016/j.ejop.2006.02.001

195. Park JS, Simpson AGB (2015) Diversity of heterotrophic protists from extremely hypersaline habitats. Ann Anat 166:422-437. https://doi.org/10.1016/j.protis.2015.06.001

196. Geisen S, Bonkowski M, Zhang J, De Jonckheere JF (2015) Heterogeneity in the genus Allovahlkampfia and the description of the new genus Parafumarolamoeba (Vahlkampfiidae; Heterolobosea). Eur J Protistol 51:335-349. https://doi.org/10.1016/j. ejop.2015.05.003

197. Baumgartner M, Eberhardt S, De Jonckheere JF, Stetter KO (2009) Tetramitus thermacidophilus $\mathrm{n}$. sp., an amoeboflagellate from acidic hot springs. J Eukaryot Microbiol 56:201-206. https ://doi.org/10.1111/j.1550-7408.2009.00390.x

198. Visvesvara GS, Sriram R, Qvarnstrom Y et al (2009) Paravahlkampfia francinae $\mathrm{n}$. sp. masquerading as an agent of primary amoebic meningoencephalitis. J Eukaryot Microbiol 56:357366. https://doi.org/10.1111/j.1550-7408.2009.00410.x

199. O'Kelly CJ, Silberman JD, Amaral Zettler LA et al (2003) Monopylocystis visvesvarai $\mathrm{n}$. gen., n. sp. and Sawyeria marylandensis n. gen., n. sp.: two new amitochondrial heterolobosean amoebae from anoxic environments. Ann Anat 154:281-290. https://doi. org/10.1078/143446103322166563

200. Barbera MJ, Ruiz-Trillo I, Tufts JYA et al (2010) Sawyeria marylandensis (Heterolobosea) has a hydrogenosome with novel metabolic properties. Eukaryot Cell 9:1913-1924. https://doi. org/10.1128/EC.00122-10
201. Broers CA, Stumm CK, Vogels GD, Brugerolle G (1990) Psalteriomonas lanterna gen. nov., sp. nov., a free-living amoeboflagellate isolated from freshwater anaerobic sediments. Eur J Protistol 25:369-380. https://doi.org/10.1016/S0932-4739(11)80130-6

202. de Graaf RM, Duarte I, van Alen TA et al (2009) The hydrogenosomes of Psalteriomonas lanterna. BMC Evol Biol 9:287. https ://doi.org/10.1186/1471-2148-9-287

203. Pánek T, Silberman JD, Yubuki N et al (2012) Diversity, evolution and molecular systematics of the Psalteriomonadidae, the main lineage of anaerobic/microaerophilic heteroloboseans (excavata: discoba). Protist 163:807-831. https://doi. org/10.1016/j.protis.2011.11.002

204. Pánek T, Simpson AGB, Hampl V, Čepička I (2014) Creneis carolina gen. et sp. nov. (Heterolobosea), a novel marine anaerobic protist with strikingly derived morphology and life cycle. Ann Anat. https://doi.org/10.1016/j.protis.2014.05.005

205. Smirnov AV, Fenchel T (1996) Vahlkampfia anaerobica n. sp. and Vannella peregrinia n. sp. (Rhizopoda) — anaerobic amoebae from a marine sediment. Arch Protistenkd 147:189-198. https:// doi.org/10.1016/S0003-9365(96)80033-9

206. Lang BF, Burger G, O'Kelly CJ et al (1997) An ancestral mitochondrial DNA resembling a eubacterial genome in miniature. Nature 387:493-497. https://doi.org/10.1038/387493a0

207. Lara E, Chatzinotas A, Simpson AGB (2006) Andalucia (n. gen.)-the deepest branch within jakobids (Jakobida; Excavata), based on morphological and molecular study of a new flagellate from soil. J Eukaryot Microbiol 53:112-120. https://doi.org/10. 1111/j.1550-7408.2005.00081.x

208. He D, Fu C-J, Baldauf SL (2015) Multiple origins of eukaryotic cox15 suggest horizontal gene transfer from bacteria to jakobid mitochondrial DNA. Mol Biol Evol 33:122-133. https://doi. org $/ 10.1093 / \mathrm{molbev} / \mathrm{msv} 201$

209. Burger G, Gray MW, Forget L, Lang BF (2013) Strikingly bacteria-like and gene-rich mitochondrial genomes throughout jakobid protists. Genome Biol Evol 5:418-438. https://doi.org/10.1093/ gbe/evt008

210. Leger MM, Eme L, Hug LA, Roger AJ (2016) Novel hydrogenosomes in the microaerophilic jakobid Stygiella incarcerata. Mol Biol Evol MSW. https://doi.org/10.1093/molbev/msw103

211. Dolezal P, Dagley MJ, Kono M et al (2010) The essentials of protein import in the degenerate mitochondrion of Entamoeba histolytica. PLoS Pathog 6:e1000812. https://doi.org/10.1371/ journal.ppat. 1000812

212. Rada P, Makki AR, Zimorski V et al (2015) N-terminal presequence-independent import of phosphofructokinase into hydrogenosomes of Trichomonas vaginalis. Eukaryot Cell 14:1264-1275. https://doi.org/10.1128/EC.00104-15

213. Garg S, Stölting J, Zimorski V et al (2015) Conservation of transit peptide-independent protein import into the mitochondrial and hydrogenosomal matrix. Genome Biol Evol 7:2716-2726. https ://doi.org/10.1093/gbe/evv175

214. Xu F, Jerlström-Hultqvist J, Einarsson E et al (2014) The genome of Spironucleus salmonicida highlights a fish pathogen adapted to fluctuating environments. PLoS Genet 10:e1004053. https:// doi.org/10.1371/journal.pgen.1004053

215. Zhang Q, Táborský P, Silberman JD et al (2015) Marine isolates of Trimastix marina form a plesiomorphic deep-branching lineage within Preaxostyla, separate from other known trimastigids (Paratrimastix n. gen.). Protist 166:468-491. https://doi. org/10.1016/j.protis.2015.07.003

216. Tovar J, León-Avila G, Sánchez LB et al (2003) Mitochondrial remnant organelles of Giardia function in iron-sulphur protein maturation. Nature 426:172-176. https://doi.org/10.1038/natur $\mathrm{e} 01945$

217. Rada P, Smid O, Sutak R et al (2009) The monothiol singledomain glutaredoxin is conserved in the highly reduced 
mitochondria of Giardia intestinalis. Eukaryot Cell 8:15841591. https://doi.org/10.1128/EC.00181-09

218. Dolezal P, Šmid O, Rada P et al (2005) Giardia mitosomes and trichomonad hydrogenosomes share a common mode of protein targeting. Proc Natl Acad Sci USA 102:10924-10929. https:// doi.org/10.1073/pnas.0500349102

219. Jedelský PL, Dolezal P, Rada P et al (2011) The minimal proteome in the reduced mitochondrion of the parasitic protist Giardia intestinalis. PLoS One 6:e17285. https://doi. org/10.1371/journal.pone.0017285

220. Rout S, Zumthor JP, Schraner EM et al (2016) An interactomecentered protein discovery approach reveals novel components involved in mitosome function and homeostasis in Giardia lamblia. PLoS Pathog 12:e1006036. https://doi.org/10.1371/journ al.ppat. 1006036

221. Regoes A, Zourmpanou D, León-Avila G et al (2005) Protein import, replication, and inheritance of a vestigial mitochondrion. J Biol Chem 280:30557-30563. https://doi.org/10.1074/jbc. M500787200

222. Jerlström-Hultqvist J, Einarsson E, Xu F et al (2013) Hydrogenosomes in the diplomonad Spironucleus salmonicida. Nat Commun 4:2493. https://doi.org/10.1038/ncomms3493

223. Millet COM, Cable J, Lloyd D (2010) The diplomonad fish parasite Spironucleus vortens produces hydrogen. J Eukaryot Microbiol 57:400-404. https://doi.org/10.111 1/j.1550-7408.2010.00499.x

224. Horváthová L, Šafaříková L, Basler M et al (2012) Transcriptomic identification of iron-regulated and iron-independent gene copies within the heavily duplicated Trichomonas vaginalis genome. Genome Biol Evol 4:1017-1029. https://doi. org/10.1093/gbe/evs078

225. Beltrán NC, Horváthová L, Jedelský PL et al (2013) Iron-induced changes in the proteome of Trichomonas vaginalis hydrogenosomes. PLoS One 8:e65148. https://doi.org/10.1371/journ al.pone. 0065148

226. Gorrell TE (1985) Effect of culture medium iron content on the biochemical composition and metabolism of Trichomonas vaginalis. J Bacteriol 161:1228-1230

227. Figueroa-Angulo E, Calla-Choque J, Mancilla-Olea M, Arroyo R (2015) RNA-binding proteins in Trichomonas vaginalis: atypical multifunctional proteins. Biomolecules 5:3354-3395. https://doi. org/10.3390/biom5043354

228. Clemens DL, Johnson PJ (2000) Failure to detect DNA in hydrogenosomes of Trichomonas vaginalis by nick translation and immunomicroscopy. Mol Biochem Parasitol 106:307-313. https://doi.org/10.1016/S0166-6851(99)00220-0

229. Dolezal P, Dancis A, Lesuisse E et al (2007) Frataxin, a conserved mitochondrial protein, in the hydrogenosome of Trichomonas vaginalis. Eukaryot Cell 6:1431-1438. https://doi. org/10.1128/EC.00027-07

230. Sutak R, Dolezal P, Fiumera HL et al (2004) Mitochondrial-type assembly of FeS centers in the hydrogenosomes of the amitochondriate eukaryote Trichomonas vaginalis. Proc Natl Acad Sci USA 101:10368-10373. https://doi.org/10.1073/pnas.04013 19101

231. Schneider RE, Brown MT, Shiflett AM et al (2011) The Trichomonas vaginalis hydrogenosome proteome is highly reduced relative to mitochondria, yet complex compared with mitosomes. Int J Parasitol 41:1421-1434. https://doi.org/10.1016/j. ijpara.2011.10.001

232. Smutná T, Pilarová K, Tarábek J et al (2014) Novel functions of an iron-sulfur flavoprotein from Trichomonas vaginalis hydrogenosomes. Antimicrob Agents Chemother 58:3224-3232. https://doi.org/10.1128/AAC.02320-13

233. Ferry JG (1997) Enzymology of the fermentation of acetate to methane by Methanosarcina thermophila. BioFactors 6:25-35

234. Zhao T, Cruz F, Ferry JG (2001) Iron-sulfur flavoprotein (Isf) from Methanosarcina thermophila is the prototype of a widely distributed family. J Bacteriol 183:6225-6233. https://doi. org/10.1128/JB.183.21.6225-6233.2001

235. Hampl V, Silberman JD, Stechmann A et al (2008) Genetic evidence for a mitochondriate ancestry in the "amitochondriate" flagellate Trimastix pyriformis. PLoS One 3:e1383. https://doi. org/10.1371/journal.pone.0001383

236. Kurihara T, Mihara H, Kato S-I et al (2003) Assembly of ironsulfur clusters mediated by cysteine desulfurases, IscS, CsdB and CSD, from Escherichia coli. Biochim Biophys Acta 1647:303309. https://doi.org/10.1016/S1570-9639(03)00078-5

237. Loiseau L, Gerez C, Bekker M et al (2007) ErpA, an iron sulfur $(\mathrm{Fe} \mathrm{S})$ protein of the A-type essential for respiratory metabolism in Escherichia coli. Proc Natl Acad Sci USA 104:13626-13631. https://doi.org/10.1073/pnas.0705829104

238. Lu J, Yang J, Tan G, Ding H (2008) Complementary roles of SufA and IscA in the biogenesis of iron-sulfur clusters in Escherichia coli. Biochem J 409:535-543. https://doi.org/10.1042/ BJ20071166

239. Jensen LT, Culotta VC (2000) Role of Saccharomyces cerevisiae ISA1 and ISA2 in iron homeostasis. Mol Cell Biol 20:3918-3927

240. Johnson DC, Unciuleac MC, Dean DR (2006) Controlled expression and functional analysis of iron-sulfur cluster biosynthetic components within Azotobacter vinelandii. J Bacteriol 188:7551-7561. https://doi.org/10.1128/JB.00596-06

241. Boyd ES, Thomas KM, Dai Y et al (2014) Interplay between oxygen and $\mathrm{Fe}-\mathrm{S}$ cluster biogenesis: insights from the Suf pathway. Biochemistry 53:5834-5847. https://doi.org/10.1021/bi500488r

242. Riboldi GP, Larson TJ, Frazzon J (2011) Enterococcus faecalis sufCDSUB complements Escherichia coli sufABCDSE. FEMS Microbiol Lett 320:15-24. https://doi.org/10.111 $1 /$ j.1574-6968.2011.02284.x

243. Riboldi GP, Verli H, Frazzon J (2009) Structural studies of the Enterococcus faecalis SufU [Fe-S] cluster protein. BMC Biochem 10:3-10. https://doi.org/10.1186/1471-2091-10-3

244. Xu XM, Møller SG (2004) AtNAP7 is a plastidic SufC-like ATP-binding cassette/ATPase essential for Arabidopsis embryogenesis. Proc Natl Acad Sci USA 101:9143-9148. https://doi. org/10.1073/pnas.0400799101

245. Xu XM, Adams S, Chua N-H, Møller SG (2005) AtNAP1 represents an atypical SufB protein in Arabidopsis plastids. J Biol Chem 280:6648-6654. https://doi.org/10.1074/jbc.M413082200

246. Møller SG, Kunkel T, Chua NH (2001) A plastidic ABC protein involved in intercompartmental communication of light signaling. Genes Dev 15:90-103. https://doi.org/10.1101/gad.850101

247. Romsang A, Duang-Nkern J, Leesukon P et al (2014) The ironsulphur cluster biosynthesis regulator IscR contributes to iron homeostasis and resistance to oxidants in Pseudomonas aeruginosa. PLoS One 9:e86763. https://doi.org/10.1371/journ al.pone. 0086763

248. van der Gulik PTS, Hoff WD, Speijer D (2017) In defence of the three-domains of life paradigm. BMC Evol Biol 17:218. https:// doi.org/10.1186/s12862-017-1059-z

249. Embley TM (2006) Multiple secondary origins of the anaerobic lifestyle in eukaryotes. Philos Trans R Soc Lond B Biol Sci 361:1055-1067. https://doi.org/10.1098/rstb.2006.1844 